\title{
A new blue whale song-type described for the Arabian Sea and Western Indian Ocean
}

\author{
Salvatore Cerchio ${ }^{1,2,3, *}$, Andrew Willson ${ }^{4}$, Emmanuelle C. Leroy ${ }^{5}$, \\ Charles Muirhead ${ }^{2,6}$, Suaad Al Harthi ${ }^{7}$, Robert Baldwin ${ }^{4}$, Danielle Cholewiak ${ }^{8}$, \\ Tim Collins ${ }^{9}$, Gianna Minton ${ }^{10}$, Tahina Rasoloarijao ${ }^{1,11}$, Tracey L. Rogers ${ }^{5}$, \\ Maïa Sarrouf Willson ${ }^{7}$ \\ ${ }^{1}$ African Aquatic Conservation Fund, Chilmark, MA 02535, USA \\ ${ }^{2}$ New England Aquarium, Anderson Cabot Center for Ocean Life, Boston, MA 02110, USA \\ ${ }^{3}$ Center for Coastal Studies, Provincetown, MA 02657, USA \\ ${ }^{4}$ Five Oceans Environmental Services LLC, Shatti al Qurm, Muscat PC131, Sultanate of Oman \\ ${ }^{5}$ Evolution and Ecology Research Centre, School of Biological, Earth and Environmental Sciences, \\ University of New South Wales, Sydney, NSW 2052, Australia \\ ${ }^{6}$ Division of Marine Science and Conservation, Duke University Marine Laboratory, Beaufort, NC 28516, USA \\ ${ }^{7}$ Environment Society of Oman, Ruwi PC112, Sultanate of Oman \\ ${ }^{8}$ NOAA Fisheries, Northeast Fisheries Science Center, Protected Species Branch, Woods Hole, MA 02543, USA \\ ${ }^{9}$ Wildlife Conservation Society, Ocean Giants Program, Bronx, NY 10460, USA \\ ${ }^{10}$ Megaptera Marine Conservation, The Hague 2242 PT, Netherlands \\ ${ }^{11}$ Institut Halieutique et des Sciences Marines, Toliara 601, Madagascar
}

\begin{abstract}
Blue whales Balaenoptera musculus in the Indian Ocean (IO) are currently thought to represent 2 or 3 subspecies (B. m. intermedia, B. m. brevicauda, B. m. indica), and believed to be structured into 4 populations, each with a diagnostic song-type. Here we describe a previously unreported song-type that implies the probable existence of a population that has been undetected or conflated with another population. The novel song-type was recorded off Oman in the northern IO/Arabian Sea, off the western Chagos Archipelago in the equatorial central IO, and off Madagascar in the southwestern IO. As this is the only blue whale song that has been identified in the western Arabian Sea, we label it the 'Northwest Indian Ocean' song-type to distinguish it from other regional song-types. Spatiotemporal variation suggested a distribution west of $70^{\circ} \mathrm{E}$, with potential affinity for the northern IO/Arabian Sea, and only minor presence in the southwestern IO. Timing of presence off Oman suggested that intensive illegal Soviet whaling that took 1294 blue whales in the 1960s likely targeted this population, as opposed to the more widely distributed 'Sri Lanka' acoustic population as previously assumed. Based upon geographic distribution and potential aseasonal reproduction found in the Soviet catch data, we suggest that if there is a northern IO subspecies (B. m. indica), it is likely this population. Moreover, the potentially restricted range, intensive historic whaling, and the fact that the song-type has been previously undetected, suggests a small population that is in critical need of status assessment and conservation action.
\end{abstract}

KEY WORDS: Blue whale $\cdot$ Pygmy blue whale $\cdot$ Endangered population $\cdot$ Passive acoustics $\cdot$ Whale song $\cdot$ Arabian Sea $\cdot$ Western Indian Ocean

\section{INTRODUCTION}

Resolving the taxonomy and population structure of baleen whales remains an essential process in

*Corresponding author: scerchio@gmail.com defining population status and understanding conservation management requirements. Blue whales Balaenoptera musculus in the Southern Hemisphere are currently classified into 2,3 , or 4 subspecies, 
depending on scientific opinion, with distinctions based on morphology, genetics, acoustics, and known distribution. These include the Antarctic blue whale B. m. intermedia Burmeister, 1871, the 'pygmy' blue whale $B$. m. brevicauda Ichihara, 1966, the northern Indian Ocean blue whale B. m. indica Blyth, 1859, and a currently unnamed Chilean blue whale $B$. musculus ssp. (Rice 1998, Pastene et al. 2020, Society for Marine Mammalogy Committee on the Taxonomy ${ }^{\mathbf{1}}$ ). The absence of dedicated biological studies and genetic sampling of all blue whale populations across the Southern Hemisphere has meant that their taxonomy and population differentiation have not been resolved. However, the most widely accepted taxonomic division is between the Antarctic blue whale and the pygmy blue whale subspecies, supported by morphological and distributional differences (Branch et al. 2007a,b, 2009). The pygmy subspecies is considered to be structured into several populations, generally defined by song-type and range (McDonald et al. 2006; see below). The classification of a northern Indian Ocean population as a separate subspecies, B. m. indica, as opposed to a regional population of pygmy blue whale, is debated and without scientific consensus (Rice 1998, Branch
\& Mikhalev 2008). Irrespective of taxonomic classification, a population reportedly resides year-round in the northern Indian Ocean, ranging from the Arabian Peninsula in the west, to at least Sri Lanka in the east, and south at least to the Maldives (Rice 1998, Branch et al. 2007b, Branch \& Mikhalev 2008, Anderson et al. 2012, Ilangakoon \& Sathasivam 2012, de Vos et al. 2014).

The vocal behavior of blue whales globally has been characterized by regional stereotyped song-types (Fig. 1) that are thought to be diagnostic to populations, under the implicit assumption that individuals from different regional populations do not switch songs and thus adhere to distinctive song-types (McDonald et al. 2006, Branch et al. 2007b, Širović et al. 2018). These have been referred to as 'acoustic populations' (McDonald et al. 2006), a term we use whenever discussing a group that is defined by shared song and therefore as a proxy for a regional or biological population (both males and females, not only the singing male portion of a population). Recordings from the Indian Ocean include one songtype from Antarctic blue whales (Fig. 1d), which are distributed around Antarctica during the summer and migrate to lower-latitude wintering regions that

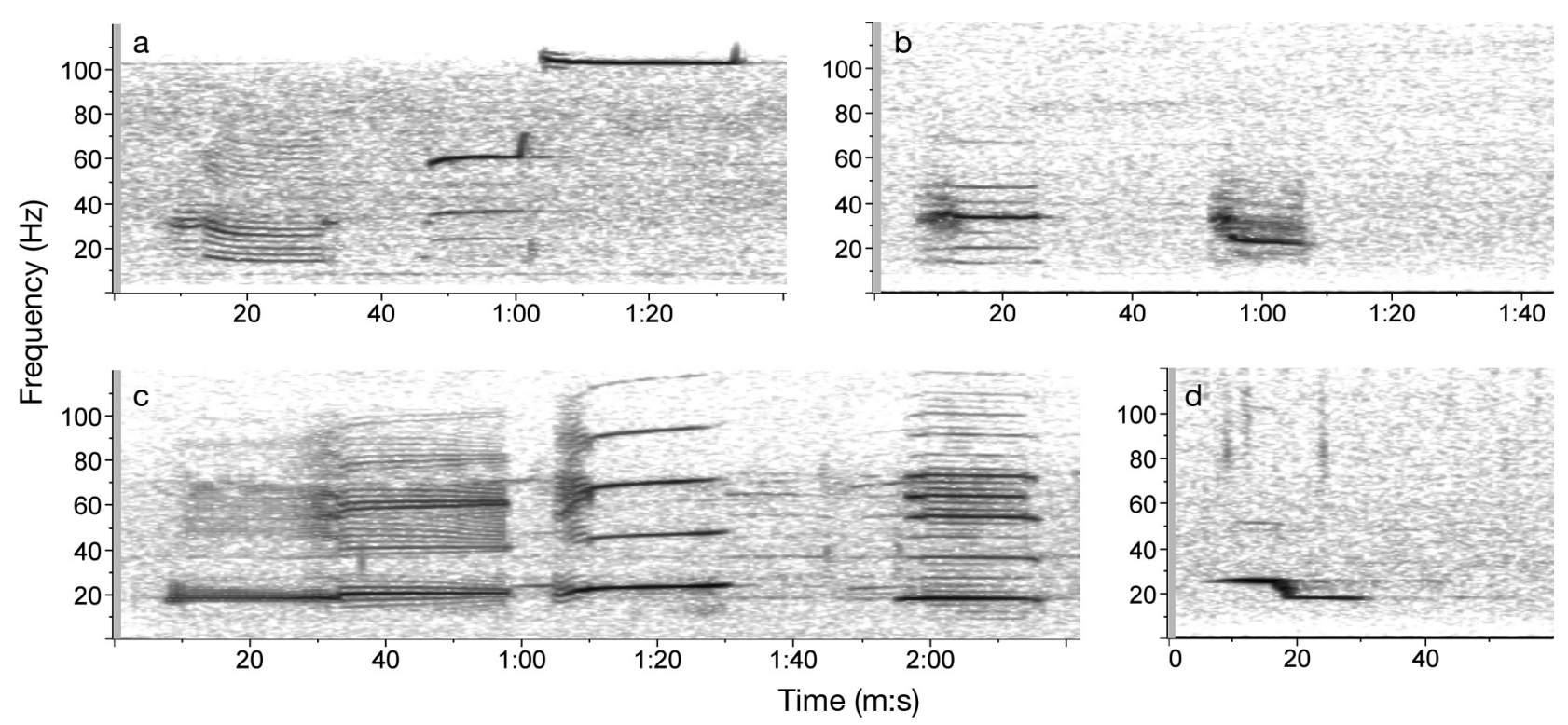

Fig. 1. Example spectrograms of recognized blue whale songs in the Indian Ocean. Each panel represents a single phrase of (a) the Central Indian Ocean/Sri Lanka song-type (from CTBTO Deigo Garcia H08N1 hydrophone, April 2009, 250 Hz sample rate [SR], 512-point FFT, $75 \%$ overlap, Hann window); (b) the Southwest Indian Ocean/Madagascar song-type (from Nosy Be, Madagascar, December 2016, 2000 Hz SR, 4096-point FFT, 75 \% overlap, Hann window); (c) the Southeast Indian Ocean/Australia song-type (from IMOS Perth Canyon hydrophone, March 2008, 500 Hz SR, 1024-point FFT, $75 \%$ overlap, Hann window); and (d) the circumpolar Antarctic song-type (from Nosy Be, Madagascar, July 2017, $2000 \mathrm{~Hz}$ SR, 4096-point FFT, 75\% overlap, Hann window). All figures are presented at standardized temporal scale and frequency band (120 Hz), and spectrogram parameters resulting in frequency resolution of $0.5 \mathrm{~Hz}$ and temporal resolution of $0.5 \mathrm{~s}$

1https://www.marinemammalscience.org/species-information/list-marine-mammal-species-subspecies/ 
remain poorly defined and unstudied (Branch et al. $2007 \mathrm{~b}$ ). There are also recordings of at least 3 regional song-types that have been attributed to either pygmy or northern Indian Ocean populations (Fig. 1a-c) and have been referred to alternatively by the ocean basin region in which they occur (McDonald et al. 2006, Širović et al. 2018) or by the location from which they were first recorded (Samaran et al. 2010a, 2013, Stafford et al. 2011, Leroy et al. 2018b). Pygmy blue whales are distributed in tropical to temperate latitudes with a southern limit of approx. $54^{\circ} \mathrm{S}$, and their year-round movement patterns are poorly understood (Branch et al. 2007a,b). In the southwest Indian Ocean, one pygmy blue whale acoustic population is defined by the 'SWIO' or 'Madagascar' song-type (Fig. 1b), heard from the Madagascar Plateau to the central Indian Ocean (Ljungblad et al. 1998, McDonald et al. 2006, Samaran et al. 2013). A second pygmy acoustic population in the southeast Indian Ocean is defined by the 'SEIO' or 'Australia' song-type (Fig. 1c), heard from the central Indian Ocean to the west coast of Australia (McDonald et al. 2006, Samaran et al. 2013, Širović et al. 2018). In the central Indian Ocean, there is an acoustic population defined by the 'Sri Lanka' or 'NIO' song-type (Fig. 1a), which was first documented off eastern Sri Lanka from boat-based recordings in the 1980s (Alling \& Payne 1985, Alling et al. 1991, McDonald et al. 2006). Although there are no other published accounts of blue whale song in the Arabian Sea or elsewhere in the northern Indian Ocean aside from eastern Sri Lanka, this Sri Lanka acoustic population has been assumed to be synonymous with the northern Indian Ocean population, or subspecies (Branch et al. 2007b, Anderson et al. 2012), and as such McDonald et al. (2006) referred to it as the NIO song. Since the early work of Alling et al. (1991), the Sri Lanka song-type has been documented in the equatorial Chagos Archipelago, as far south as the Amsterdam Island $\left(43^{\circ} \mathrm{S}\right)$ and Crozet Island $\left(46^{\circ} \mathrm{S}\right)$ basins, and even outside the Indian Ocean in the equatorial eastern South Atlantic off Angola, interpreted as a likely extralimital individual (Cerchio et al. 2010, Samaran et al. 2010a, 2013, Stafford et al. 2011, Leroy et al. 2018b). Therefore, there is an apparent incongruence between the concept of a regionally resident population/subspecies in the northern Indian Ocean and the predominant documentation of its putative song-type in the tropical and temperate latitudes of the Southern Hemisphere.

Most blue whale populations were hunted to near extirpation in the $20^{\text {th }}$ century (Branch et al. 2007b). Of particular consequence was a period of illegal pelagic whaling by the Soviet Union during 19631967 when 1294 blue whales were caught in the northwestern Indian Ocean, south to $5^{\circ} \mathrm{S}$ (Mikhalev 1996, 2000; data held by the International Whaling Commission, represented in Fig. 2). The largest numbers of catches in the Arabian Sea were off northern Somalia (Gulf of Aden) and the Arabian Peninsula (ca. $10^{\circ}-17^{\circ} \mathrm{N}, 45^{\circ}-55^{\circ} \mathrm{E}$ ), with additional smaller clusters in the central-eastern Arabian Sea off Lakshadweep/Maldives/western Sri Lanka (ca. $5^{\circ}-10^{\circ} \mathrm{N}, 65^{\circ}-$ $80^{\circ} \mathrm{E}$ ) and off the Indus Canyon in the northeastern Arabian Sea (ca. $\left.22^{\circ}-24^{\circ} \mathrm{N}, 66^{\circ}-68^{\circ} \mathrm{E}\right)$. These catches are generally allocated to the northern Indian Ocean

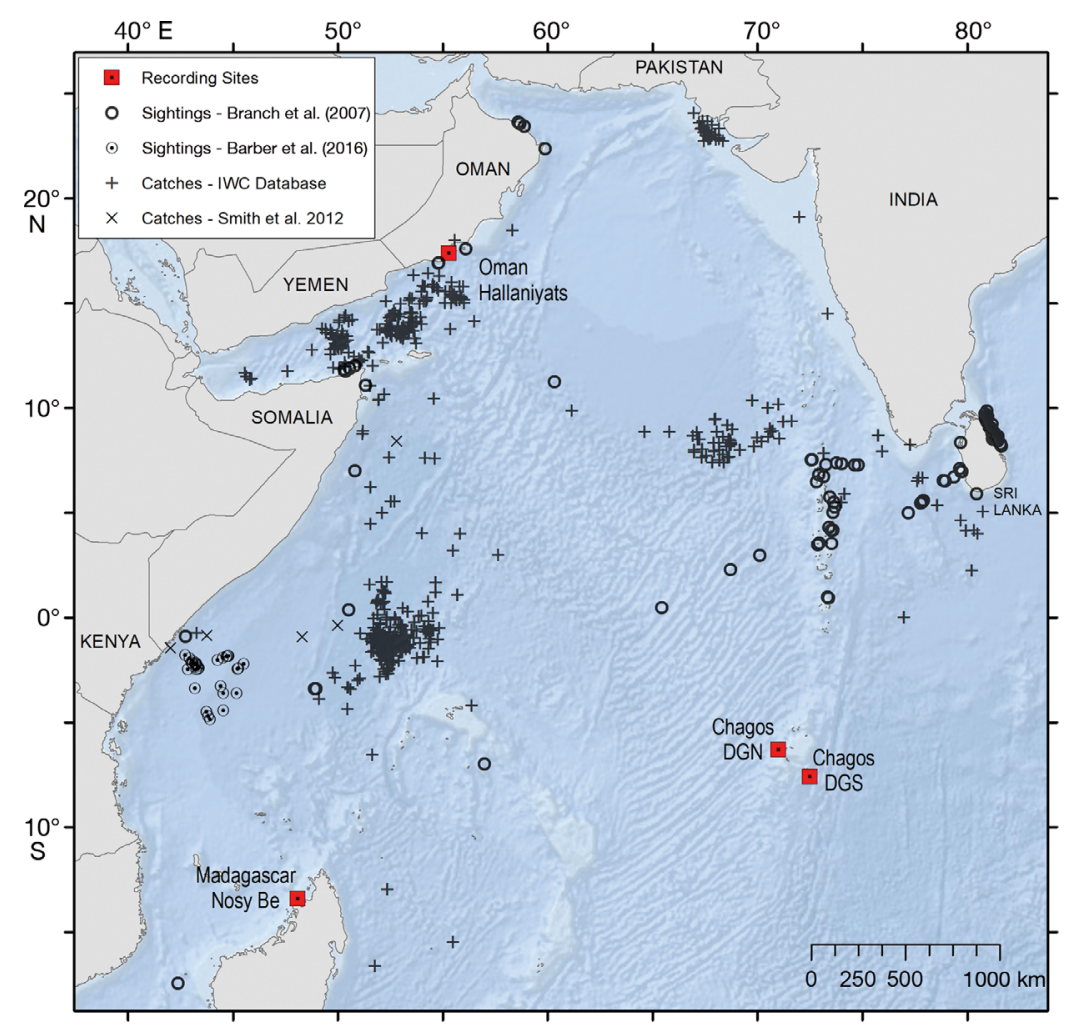

Fig. 2. Western Indian Ocean, showing recording sites in Oman (Hallaniyats Bay), Chagos Archipelago (Diego Garcia North [DGN] and Diego Garcia South [DGS]), and Madagascar (Nosy Be). Also depicted are catches of pygmy blue whales from the International Whaling Commission (IWC) individual catch database Version 6.1, 18 July 2016 (C. Allison unpubl.), including illegal Soviet catches from Mikhalev (1996, 2000), 19 th $^{\text {th }}$ century (1853) catches from Smith et al. (2012), and blue whale sightings reported by Branch et al. (2007b) and Barber et al. (2016) 
population (also referred to as the Sri Lanka acoustic population) (Branch et al. 2007b, Anderson et al. 2012). More recent visual observations confirm that blue whales continue to utilize the habitat in all of these regions, including off Oman (Minton et al. 2010, Willson et al. 2019), Pakistan (Moazzam \& Nawaz 2019), western India (Sutaria et al. 2016, 2017), the Maldives, and Sri Lanka (Anderson et al. 2012). Large numbers of catches were also made north of the Seychelles between ca. $2^{\circ} \mathrm{N}$ and $5^{\circ} \mathrm{S}$, and recently, 30 visual sightings were made further west off Kenya between $2^{\circ}$ and $5^{\circ} \mathrm{S}$ during geophysical surveys in the Austral spring; the timing of these records suggests that this is a potential breeding area, although it is not clear if these represent the Antarctic, Southwest Indian Ocean pygmy, or northern Indian Ocean subspecies/population (Branch et al. 2007b, Barber et al. 2016).

We report here a baleen whale song-type that, to our knowledge, has not been previously described. The song was recorded at 3 disparate locations in the Western Indian Ocean separated by approximately $3500 \mathrm{~km}$ during 3 independent efforts of long-term passive acoustic monitoring. The locations include the waters off Oman in the western Arabian Sea, around the Chagos Archipelago in the central Indian Ocean, and off northwest Madagascar in the southwest Indian Ocean (Fig. 2). Although it can be difficult to definitively attribute a remotely recorded, previously undescribed song to a species, we believe it is a blue whale song-type based on sightings of blue whales within hours of recording the song off Oman, along with the general acoustic description of the song. Given that this is a newly described blue whale song, we discuss how the discovery impacts our current understanding of blue whale population structure and behavior in the Indian Ocean.

\section{MATERIALS AND METHODS}

\subsection{Oman data collection}

During 2011-2012, passive acoustic monitoring was conducted off the coast of Oman in Hallaniyats Bay targeting Arabian Sea humpback whales Megaptera novaeangliae (Cerchio et al. 2016). A Wildlife Acoustics SM2M autonomous archival recorder was placed in shallow water at $16 \mathrm{~m}$ depth in close proximity to the shelf break (within $<1 \mathrm{~km}$ ), and therefore had an acoustic 'view' of nearby deep water. All Oman data presented here were recorded at that site $\left(17.40^{\circ} \mathrm{N}\right.$, $\left.55.31^{\circ} \mathrm{E}\right)$. The SM2M recorder specifications indicate that it has a flat response from $2 \mathrm{~Hz}$ to $30 \mathrm{kHz}( \pm 2 \mathrm{~dB})$,

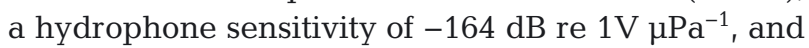
was conditioned with a $3 \mathrm{~Hz}$ high-pass filter and $12 \mathrm{~dB}$ gain. Three deployments were conducted with varying recording parameters: 23 November 2011 to 20 February 2012, continuous recording at $16 \mathrm{kHz}$ sample rate (SR) and 16-bit depth; 24 February to 26 March 2012, continuous recording at $32 \mathrm{kHz}$ SR and 16-bit depth; and 29 March to 21 October 2012, 33\% duty cycled recording (10 min every $30 \mathrm{~min}$ ) at $22 \mathrm{kHz}$ SR and 16-bit depth.

\subsection{Madagascar data collection}

During 2016-2019, passive acoustic monitoring was conducted off northwest Madagascar in the Nosy Be region, targeting Southern Hemisphere blue whales and other baleen whales (Cerchio et al. 2018). An Ocean Instruments SoundTrap 300-STD autonomous archival recorder was deployed during 4 approximately 4 mo deployments from early December 2016 to early April 2018 and 2 approximately 6 mo deployments from early April 2018 to early April 2019. The instrument was anchored just off the shelf break at the same approximate position $\left(13.28^{\circ} \mathrm{S}\right.$, $48.01^{\circ} \mathrm{E}$ ) at depths ranging from 225 to $260 \mathrm{~m}$ across deployments and suspended approximately $4 \mathrm{~m}$ above the sea bottom. The SoundTrap recorder specifications indicate that it has a flat response from $20 \mathrm{~Hz}$ to $60 \mathrm{kHz}( \pm 3 \mathrm{~dB})$ with a $-9 \mathrm{~dB}$ roll-off at $10 \mathrm{~Hz}$ and

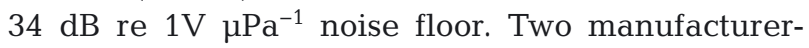
calibrated recorders were used, and hydrophone sensitivity plus system gain was $-171.7 \mathrm{~dB}$ re $1 \mathrm{~V}$ $\mu \mathrm{Pa}^{-1}$ during December 2016 to April 2018, and $-174.1 \mathrm{~dB}$ re $1 \mathrm{~V} \mu \mathrm{Pa}^{-1}$ during April 2018 to April 2019. During the 4 mo deployments, recordings were made at $50 \%$ duty cycle (30 min every $60 \mathrm{~min}$ ), $24 \mathrm{kHz}$ SR, and a 16-bit depth; during the $6 \mathrm{mo}$ deployments, recordings were made at $33 \%$ duty cycle (20 min every $60 \mathrm{~min}$ ) at either 24 or $96 \mathrm{kHz}$ SR and a 16-bit depth.

\subsection{Chagos Archipelago data collection}

The Chagos Archipelago hydroacoustic dataset was obtained from the International Data Centre of the Comprehensive Nuclear Test-Ban Treaty Organisation (CTBTO) in Vienna. Data were recorded at the CTBTO hydrophone station HA08 located off Diego Garcia Island, an atoll of the Chagos Archipelago in the central Indian Ocean. The HA08 station is com- 
prised of 2 hydrophone triplets: a northern one, H08N, referred as Diego Garcia North (DGN, 06.3 $\mathrm{S}$, $071.0^{\circ} \mathrm{E}$ ), and a southern one, H08S, referred as Diego Garcia South (DGS, 07.6 $\mathrm{S}, 072.5^{\circ} \mathrm{E}$ ). Hydrophones within the triplets are separated by approximately $2.5 \mathrm{~km}$, and DGN and DGS are about $220 \mathrm{~km}$ apart. DGN and DGS are believed to be independent acoustic sampling areas: the shallow depth and long north-south extension of the Chagos Bank act as an acoustic barrier between the western and eastern equatorial Indian Ocean. Sounds produced on either side of the Chagos Bank are unlikely to be heard on the other side (Pulli \& Upton 2001). Thus, the northern site (i.e. DGN records) represents the soundscape west of the island, whereas the southern site (i.e. DGS records) represents the soundscape east of the island. Hydrophones are moored in the sound fixing and ranging (SOFAR) channel (about $1000 \mathrm{~m}$ deep) and cabled to Diego Garcia Island. They acquire data continuously, with a sampling rate of $250 \mathrm{~Hz}$ and 24bit depth (see Hanson 2001 for details). Here, we used the data recorded by the hydrophones H08N1 and H08S1 from 1 January to 31 December 2010 to 2013.

\subsection{Data analysis}

For the Oman and Madagascar datasets, the original wav files were down-sampled to $2 \mathrm{kHz}$ to reduce size and increase manageability of the data set for low-frequency analysis. A manual evaluation of continuous spectrograms was conducted in Raven Pro 1.5 (Bioacoustics Research Program 2014) at parameters optimized to detect signals of low frequency baleen whales such as blue whale, fin whale Balaenoptera physalus, and Bryde's whale B. edeni (0$65 \mathrm{~Hz}$ displayed frequency band, 3 spectrogram lines per displayed page, and $30 \mathrm{~min}$ per spectrogram line for $1.5 \mathrm{~h}$ recording displayed per page, 4096-point FFT, $50 \%$ overlap, Hanning window). During the browse of spectrograms, all potential baleen whale vocalizations were logged for presence in half-hour bins, i.e. once during the first $30 \mathrm{~min}$ and once during the second $30 \mathrm{~min}$ for each hour. A review of the Madagascar data revealed extensive detections of both Southwest Indian Ocean (Madagascar) pygmy and Antarctic blue whale song-types, as well as fin whale and Antarctic minke whale B. bonaerensis songs, in addition to the less frequent occurrence of the novel song-type described in this study (Cerchio et al. 2018). After identification of the novel songtype, an additional exhaustive browse was con- ducted during the months when the novel song-type was detected. This additional analysis was undertaken to verify logged sequences of the novel songtype (particularly to distinguish between it and the more commonly occurring Antarctic blue whale song-type in the Madagascar data) and to identify and log missed detections using analysis parameters optimized for visualization of the specific song frequency band (14-35 Hz displayed frequency band, 30 min per spectrogram line, 8192-point FFT, 50\% overlap, Hanning window).

To assist the manual browsing of the more extensive 4 yr Chagos data set, an automated detection algorithm was first run on the acoustic data. This algorithm performs a dictionary-based detection by modeling mysticete vocalizations with sparse representations (Socheleau \& Samaran 2017). The method uses a decision statistic that offers optimal properties with respect to false alarm and detection probabilities (Socheleau et al. 2015). As the signal of interest is modeled using a dictionary, the detector can be used for previously unknown or understudied recurrent signals. The dictionary was created using 310 vocalizations with good signal to noise ratio (SNR), recorded at DGS in April 2010. The obtained detection time stamps were then imported into Raven Pro 1.5 as a selection table and displayed on the spectrogram for each year of data (0-125 Hz displayed band, 3 spectrogram lines per displayed page, and $20 \mathrm{~min}$ per spectrogram line, 512-point FFT, 50\% overlap, Hanning window). Spectrograms were scanned to check all detected events and to identify and remove all false detections. Periods of data without automated detections were also carefully scrutinized to identify possible false negatives. Results were then converted into a metric of hourly presence.

All logged song sequences at each of the 3 sites were evaluated for the number of singers present, estimated at 1, 2, or 3+ singers, based upon the observation of overlapping song units and apparent overlapping series of song phrases with different repetition rates and received levels (RLs). Each logged sequence was assigned a subjective rating of SNR and quality on a scale from A to D, where A exhibited strong signals with all song units detectable and multiple harmonics present and D represented song sequences in which only faint repetitive sequences of 1 song unit were detectable with no harmonics. To provide a preliminary description of spectral and temporal characteristics of the song-type, a small subset of the highest quality SNR sequences were quantitatively measured in Raven Pro 1.5. To first identify the highest RL sequences in each dataset, the logged sequences were 
ordered using the 'Peak Power' (dB) and 'Peak Frequency' (Hz) functions of Raven Pro. These were then reviewed to choose the best SNR examples, and to identify 5-10 sequences for each site in which 5-10 consecutive song phrases could be adequately measured. To minimize non-independence between measured sequences, an attempt was made to choose sequences separated by at least $1 \mathrm{~d}_{i}$ however, this was not entirely possible, as there were temporal clusters of high SNR examples, and for each site two of the measured song sequences were separated by $2-3 \mathrm{~h}$. In all cases, it was assumed with some confidence that an uninterrupted sequence of consecutive phrases with similar RL and consistent repetition rate represented a song sequence from a single individual. Measurements were made on spectrograms with frequency resolution of $0.24 \mathrm{~Hz}$ and temporal resolution of $0.2 \mathrm{~s}$ (Chagos: $250 \mathrm{~Hz} \mathrm{SR}$, 1024-point FFT, 95\% overlap; Oman \& Madagascar: 2000 Hz SR, 8192point FFT, $95 \%$ overlap; Hann window). For each of the 2 units, or notes, of the song phrase (hereafter referred to as Unit 1 and Unit 2), a Raven selection box was drawn to tightly bound the unit, and measurements included: peak frequency $(\mathrm{Hz})$, the frequency of peak power across the boxed unit; duration of the unit (s), as measured manually from start to end of the unit; duration $90 \%$ (s), the duration of the unit section with $90 \%$ of spectral energy as measured by Raven robust measurement; frequency bandwidth of the unit (Hz), as manually measured from low to high frequency. In addition, phrase duration (s) was measured from start of Unit 1 to the end of Unit 2, and repetition rate (s) of phrases was measured from the start of one phrase to start of next. SNR (dB) was measured using the 'Inband Power' function in Raven and the procedure recommended by the Center for Conservation Bioacoustics ${ }^{2}$, comparing identical time/frequencyband selections of signal and background noise. Only units with an SNR $>8 \mathrm{~dB}$ were used in calculating descriptive statistics.

\section{RESULTS}

\subsection{Identification and description of the novel song-type}

The new baleen whale song-type reported here was first detected during the low-frequency manual browse of the Madagascar data for baleen whale diversity assessment (by S. Cerchio; Cerchio et al. 2018). In all cases, it was detected at low SNR, indicating distant animals recorded by the relatively deep-water recorders on the Madagascar continental slope. During an assessment of humpback whale song on the Oman recorders (by C. Muirhead and S. Cerchio), the same signal was detected opportunistically, prompting the systematic low-frequency browse of that dataset at the same standardized parameters used for the Madagascar assessment. Ultimately, the Oman data revealed a more frequent rate of occurrence of the song-type; however, the Oman detections were still of relatively low SNR, as would be expected from a signal originating from a deep-water source and detected on a shallow-water hydrophone. Finally, the same song-type was recognized on recordings from the deep-water CTBTO recorders off the Chagos Archipelago (by E. C. Leroy) upon viewing the song-type in Cerchio et al. (2018), prompting a review of $4 \mathrm{yr}$ of data from the DGN and DGS recording sites. As these recorders were placed at the depth of the SOFAR channel, the detection range was likely the largest, and some of the cleanest examples of the song were recorded, albeit still at a predominantly low SNR.

The song phrase consisted of 2 units arranged in a consistent simple pattern (Fig. 3), repeated in a consistent rhythm (Fig. 4), typical of song from other Balaenoptera species (Watkins et al. 1987, 2000, McDonald et al. 2006). The units appeared to have harmonically related bands, and the detection and received levels of different harmonics were related to the SNR, as would be expected based upon propagation effects in different environments and varying distances between the source and receiver. The highest SNR detections, found only off Oman and the Chagos Archipelago, indicated a fundamental frequency in the 11-12 Hz bandwidth, a 3-band pattern (first, second, and third harmonics) for Unit 1, and a 2-band pattern (first and second harmonics) for Unit 2 (Fig. 3a, Oman; Fig. 3b, Chagos). In most detections, the SNR was low, such that each unit consisted of a single band in the 22-26 Hz bandwidth, representing the second harmonic (see Fig. 4b for example from Madagascar); however, higher SNR detections indicated a 2-band pattern in Unit 1 at all sites, representing the second and third harmonics (see Fig. 3c for example from Madagascar, and Fig. 4a for example from Chagos). In high SNR examples, for which the fundamental frequency was

${ }^{2}$ https://ravensoundsoftware.com/knowledge-base/signal-to-noise-ratio-snr 
present, there were often several bands at the same approximate $11.5 \mathrm{~Hz}$ harmonic interval between 150 and $250 \mathrm{~Hz}$ (Fig. 3d), observed only off Oman (note that the Chagos data sampling rate was too low to record this bandwidth, and all examples from Madagascar were too low in SNR to observe these higher harmonics). It is worth noting that an 11-12 Hz fundamental frequency and harmonic interval is particularly low as compared to most blue whale songs, and to baleen whales in general.
The waveform revealed both tonal and amplitudemodulated sections for both units (Fig. 5). Unit 1 commenced as a tonal signal with gradual onset (Fig. 5c) and became amplitude-modulated (Fig. 5d) until termination of the unit (Fig. 5e). Unit 2 commenced as a tonal signal with gradual onset (Fig. 5f) and terminated as an amplitude-modulated signal (Fig. 5g). Spectrograms showed that the initial tonal-component of Unit 1 had the highest received levels in the second harmonic $\left(F_{1}\right)$, less in the third harmonic $\left(F_{2}\right)$,
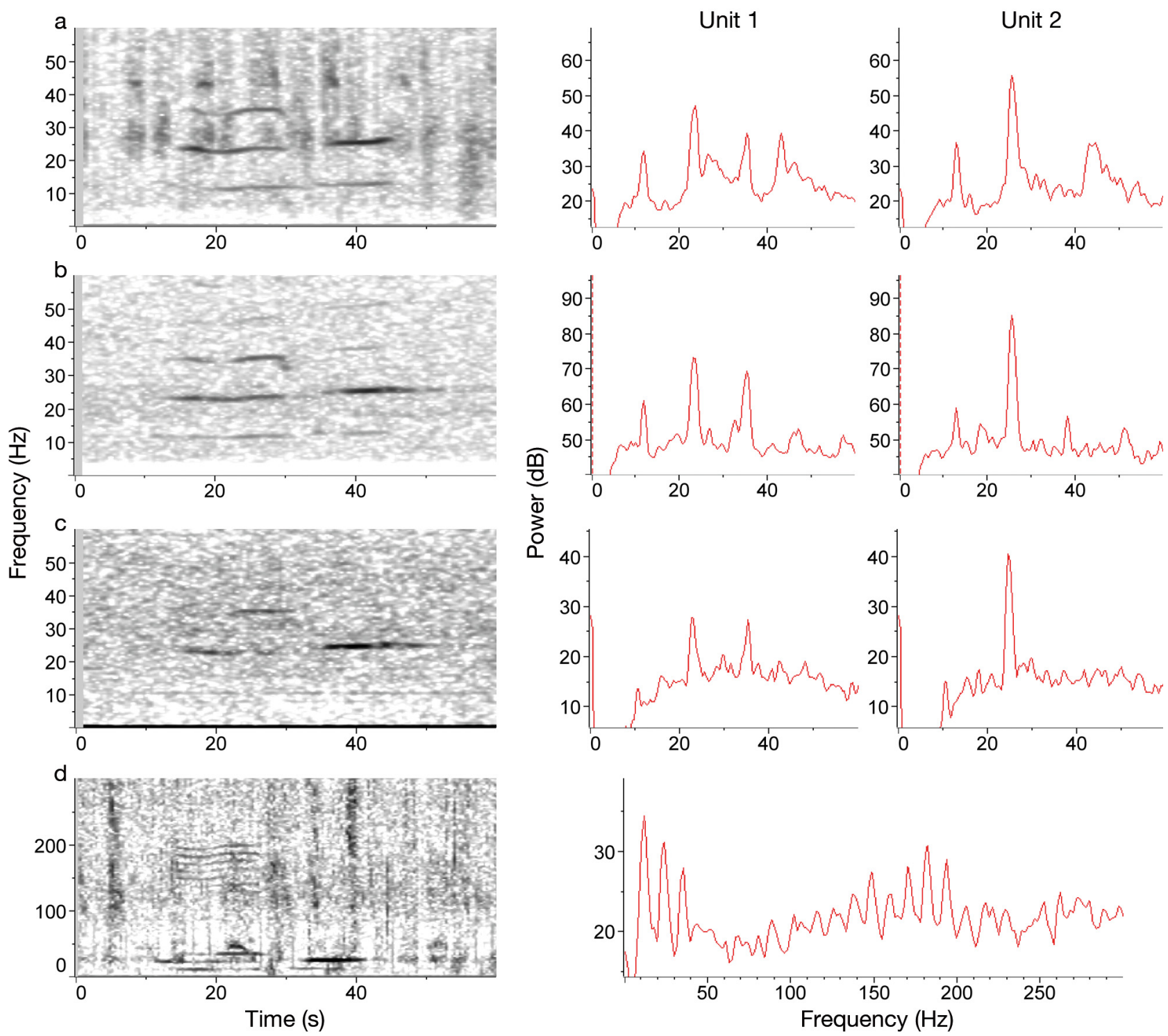

Fig. 3. Examples of the northwest Indian Ocean (NWIO) blue whale song-type, illustrating spectrograms of a single phrase, along with power spectral distributions for Units 1 and 2 separately, recorded off (a) Oman, showing the 3-band structure (first, second, and third harmonic) in Unit 1 (2000 Hz SR, 4096-point FFT, 75 \% overlap, high-pass filtered 4 Hz); (b) Diego Garcia, 3band Unit 1 (250 Hz SR, 512-point FFT, $75 \%$ overlap, high-pass filtered $4 \mathrm{~Hz}$ ); and (c) Madagascar, 2-band (second and third harmonic) Unit 1 (2000 Hz SR, 4096-point FFT, 75\% overlap, high-pass filtered 4 Hz). (d) Example from Oman, illustrating mid-frequency harmonics between 150 and $200 \mathrm{~Hz}$ present only on high signal to noise ratio (SNR) detections that also contain first harmonic band (2000 Hz SR, 2048-point FFT, $75 \%$ overlap, high-pass filtered $4 \mathrm{~Hz}$ ); note that the short repetitive vocalizations with fundamental frequency near $45 \mathrm{~Hz}$ in panels (a) and (d) are fish vocalizations 


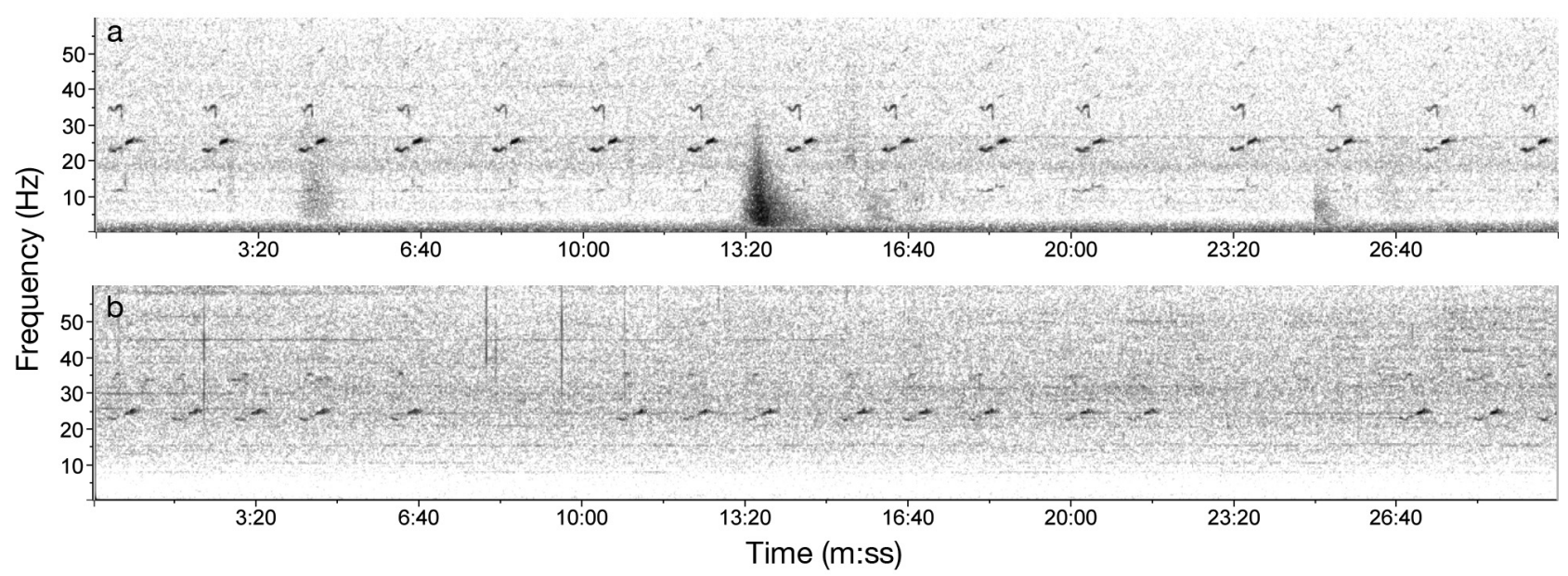

Fig. 4. Example sequences of phrases for the NWIO blue whale song-type recorded off Chagos and Madagascar, illustrating typical repetition rates and varying signal to noise ratios (SNRs). Represented are sequences of (a) a high SNR example recorded off Chagos, illustrating 3-band (first, second, and third harmonic) and 2-band (second and third harmonic) units (250 Hz SR, 1024-point FFT, $75 \%$ overlap, Hann window); and (b) a low SNR example recorded off Madagascar, illustrating 1-band (second harmonic) and 2-band (second and third harmonic) units (2000 Hz SR, 8192-point FFT, $75 \%$ overlap, Hann window)

and little (or no visible) energy in the fundamental $\left(\mathrm{F}_{0}\right)$. Similarly, Unit 2 had the highest received levels in the second harmonic and displayed an approximately $2 \mathrm{~Hz}$ frequency-modulated upsweep. Since these relationships were consistent among all locations, all time-frequency measurements were made on the second harmonic for both units, as this was the band most reliably measured and is the most informative for other datasets (Table 1). Measurements were made on 6 to 9 different series per site, with the number of measured units varying depending on the availability of units with an SNR $>8 \mathrm{~dB}$ (Table 1). Mean peak frequency of Units 1 and 2 respectively ranged from 22.6 and $24.5 \mathrm{~Hz}$ in Madagascar to 23.1 and $25.4 \mathrm{~Hz}$ off Chagos, with Oman being intermediate. The differences are congruent with a decrease in frequency over the course of the $9 \mathrm{yr}$ period during which the recordings were made (Chagos in 2010 to Madagascar in 2017 and 2018), as has been observed for other blue whale songs (McDonald et al. 2009, Leroy et al. 2018a), and therefore does not necessarily indicate regional variation. Unit 1 wavered in frequency over a $1.5-1.9 \mathrm{~Hz}$ band, whereas Unit 2 was characterized by a consistent upsweep in frequency that averaged from $1.9 \mathrm{~Hz}$ in Madagascar to $2.1 \mathrm{~Hz}$ in Chagos. Mean unit duration for Unit 1 ranged from $13.9 \mathrm{~s}$ in Madagascar to $16.6 \mathrm{~s}$ in Chagos, and for Unit 2 , it ranged from $12.8 \mathrm{~s}$ in Madagascar to $13.8 \mathrm{~s}$ in Chagos; however, the mean SNR for Madagascar Unit 1 was low at $9.9 \mathrm{~dB}$, and therefore these duration measurements may be biased low. The Raven Pro 1.5 robust measurement of $90 \%$ duration indicated less variation across sites, at 9.9-11.0 s for Unit 1. Mean phrase duration was similar at all sites, ranging only from $32.3 \mathrm{~s}$ off Oman to $33.4 \mathrm{~s}$ off both Madagascar and Chagos. The phrases were always detected in rhythmic series with strongly varying repetition rates (measured from the start of consecutive phrases), ranging from a mean of $92.6 \mathrm{~s}$ for Madagascar to $122.7 \mathrm{~s}$ off Oman and an overall range of 54.8-293.4 s across all intervals measured. Consequently, repetition rate on average was approximately $2.8-3.8 \times$ the phrase length. In most sequences, several repetitions occurred at a consistent rate interspersed with occasional longer gaps (Fig. 4a,b).

\subsection{Spatiotemporal variation}

The temporal distribution of the song-type detections over the monitored period varied substantially at the 3 sites (Fig. 6). Off the coast of Oman, the song was detected predominantly during December and January, with a more sparse distribution of detections during 6 mo from late November to late May, and it was not detected at all between June and October (Fig. 6a). During a 2 wk period in December 2011, there were $12 \mathrm{~d}$ on which a chorus of 2 or more individual singers was evident in the spectrogram during 1 to $5 \mathrm{~h} \mathrm{~d}^{-1}$. Thus mid-December was the period of peak occurrence in 2011. Lack of data from other years precludes assessment of consistency in seasonality across years.

Off the Chagos Archipelago, the song was detected at DGN on the west side of the Chagos Bank broadly throughout the year, with substantial varia- 

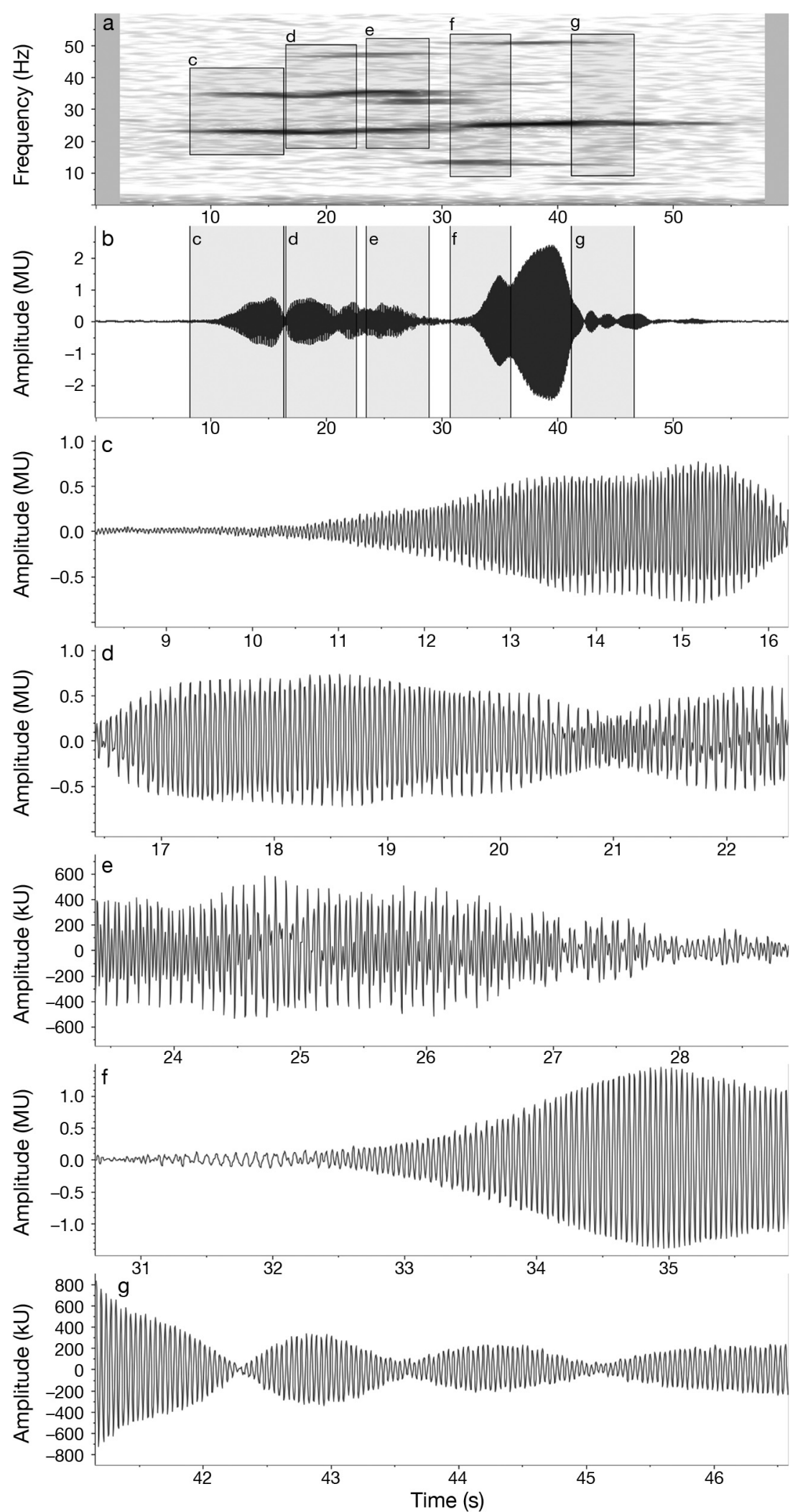

Fig. 5. (a) Spectrogram and (b) waveform of the NWIO blue whale song-type recorded on the western side of the Chagos Archipelagos, with boxes identifying waveform details of: (c) tonal signal at the start of Unit 1, (d) commencement of amplitude-modulation of Unit 1, (e) amplitude-modulation terminating Unit 1, (f) tonal signal at commencement of Unit 2, (g) amplitude-modulated termination of Unit 2 (250 Hz SR, 512-point FFT, $75 \%$ overlap, Hamming window) 
Table 1. Acoustic measurements of NWIO blue whale song for each recording site, for both song Units 1 and 2 . Measurements were made on the second harmonic of each unit, and values are expressed as averages and range (minimum-maximum). Series N: number of different series measured (representing the highest received level examples in each dataset), separated by at least $2 \mathrm{~h}$ but preferably $1 \mathrm{~d}$; Unit $\mathrm{N}$ : total number of units with a signal to noise ratio (SNR) $>8 \mathrm{~dB}$ that were measured, representing the highest SNR continuous sequence of 5-10 phrases within each series; Peak freq (Hz): frequency of peak power across boxed unit; dur (s): duration of unit as measured manually from start to end of unit; dur $90 \%$ (s): duration of unit section with $90 \%$ of spectral energy as measured by Raven Pro 1.5 robust measurement; BW (Hz): frequency bandwidth of unit as manually measured from low to high frequency; SNR (dB): SNR as measured using Raven's Inband Power; phrase dur (s): duration of a phrase as measured from start of Unit 1 to end of Unit 2; rep rate (s): repetition rate of phrases as measured from start of one phrase to start of next. Spectrographic parameters were chosen to provide frequency resolution of $0.24 \mathrm{~Hz}$ and temporal resolution of $0.20 \mathrm{~s}$ (Chagos: $250 \mathrm{~Hz}$ sample rate [SR], 1024-point FFT, 95\% overlap; Oman \& Madagascar: $2000 \mathrm{~Hz}$ SR, 8192-point FFT, $95 \%$ overlap; Hann window)

\begin{tabular}{|c|c|c|c|c|c|c|c|c|c|}
\hline & Series $N$ & Unit $\mathrm{N}$ & Peak freq $(\mathrm{Hz})$ & Dur (s) & Dur $90 \%(\mathrm{~s})$ & BW $(\mathrm{Hz})$ & SNR (dB) & Phrase dur (s) & Rep rate $(\mathrm{s})$ \\
\hline \multicolumn{10}{|c|}{ Chagos April 2010} \\
\hline Unit 1 & 6 & 46 & $\begin{array}{c}23.1 \\
(22.5-23.4)\end{array}$ & $\begin{array}{c}16.6 \\
(13.7-19.7)\end{array}$ & $\begin{array}{c}11.0 \\
(8-13.7)\end{array}$ & $\begin{array}{c}1.7 \\
(1.3-2.1)\end{array}$ & $\begin{array}{c}15.6 \\
(9.4-23.6)\end{array}$ & $\begin{array}{c}33.4 \\
(31.5-36.1)\end{array}$ & $\begin{array}{c}121 \\
(80.7-218.7)\end{array}$ \\
\hline Unit 2 & 6 & 48 & $\begin{array}{c}25.4 \\
(25.1-25.9)\end{array}$ & $\begin{array}{c}12.8 \\
(11.1-14.8)\end{array}$ & $\begin{array}{c}6.9 \\
(5.3-10)\end{array}$ & $\begin{array}{c}2.1 \\
(1.5-2.4)\end{array}$ & $\begin{array}{c}24.7 \\
(17.9-33.2)\end{array}$ & & \\
\hline \multicolumn{10}{|c|}{ Oman December 2011-March 2012} \\
\hline Unit 1 & 9 & 70 & $\begin{array}{c}22.9 \\
(22.5-23.4)\end{array}$ & $\begin{array}{c}14.9 \\
(11.2-17.9)\end{array}$ & $\begin{array}{c}9.9 \\
(5.1-12.7)\end{array}$ & $\begin{array}{c}1.6 \\
(1.0-2.2)\end{array}$ & $\begin{array}{c}12.1 \\
(8.1-17.6)\end{array}$ & $\begin{array}{c}32.3 \\
(29.8-34.8)\end{array}$ & $\begin{array}{c}122.7 \\
(54.8-293.4)\end{array}$ \\
\hline Unit 2 & 9 & 80 & $\begin{array}{c}25.1 \\
(24.9-25.6)\end{array}$ & $\begin{array}{c}11.6 \\
(9.8-13.3)\end{array}$ & $\begin{array}{c}6.5 \\
(4.7-9.2)\end{array}$ & $\begin{array}{c}2.0 \\
(1.4-2.9)\end{array}$ & $\begin{array}{c}18.0 \\
(8.2-28.0)\end{array}$ & & \\
\hline \multicolumn{10}{|c|}{ Madagascar April 2017-May 2018} \\
\hline Unit 1 & 5 & 19 & $\begin{array}{c}22.6 \\
(22.2-23.2)\end{array}$ & $\begin{array}{c}13.9 \\
(10.1-18.2)\end{array}$ & $\begin{array}{c}10.1 \\
(6.4-13.7)\end{array}$ & $\begin{array}{c}1.5 \\
(1.0-1.9)\end{array}$ & $\begin{array}{c}9.9 \\
(8.2-13.9)\end{array}$ & $\begin{array}{c}33.4 \\
(29.3-37.9)\end{array}$ & $\begin{array}{c}92.6 \\
(72.8-164.3)\end{array}$ \\
\hline Unit 2 & 9 & 48 & $\begin{array}{c}24.5 \\
(24.2-24.9)\end{array}$ & $\begin{array}{c}13.8 \\
(11.2-18)\end{array}$ & $\begin{array}{c}8.6 \\
(5.9-11.7)\end{array}$ & $\begin{array}{c}1.9 \\
(1.5-2.7)\end{array}$ & $\begin{array}{c}16.2 \\
(10.3-26.5)\end{array}$ & & \\
\hline
\end{tabular}

tion among the 4 sampled years and no consistent seasonal pattern (Fig. 6b). The most singing activity was detected from mid-January to late April, particularly in 2010, but also to a lesser extent in 2013. A second broad peak in activity occurred from October to December in 2013 and to a lesser extent in 2010. Very few detections were made between May and September in both 2010 and 2013, such that these 2 years had largely similar bi-modal distributions in occurrence. Short periods of chorusing (2 or more singers) were detected during the peak occurrence periods in April 2010 and November 2013. During 2011 and 2012, the pattern of occurrence was more dispersed throughout the year without clear peaks, with generally fewer detections and a lower proportion of hours during days when detected. Off the eastern side of Chagos, recordings from the DGS recorder had dramatically fewer detections during the 4 years (not represented in Fig. 6). The song was only detected during a 20 d period in late April 2010, with a strong peak of singing activity from 17-22 April, with choruses of 2 or more individuals on more than $50 \%$ of hours each day (detail shown in Fig. 7). This was broadly concurrent with the peak of singing activity at DGN during April 2010, but overlapping with the lull in singing during the middle of that month (Fig. 7), suggesting that a group of singers may have temporarily shifted distribution to the east side of the Chagos Bank. The song was not detected at all off DGS in 2011 and 2012, and in 2013 it was detected during only 2 hours of 1 day in mid-January.

Off Madagascar, the temporal distribution of detections was much more limited, occurring only during 2 mo from early April to late May, and consistent in

Fig. 6. Hourly occurrence of detections of the NWIO blue whale song-type at 3 sites: (a) Hallaniyats Bay, Oman; (b) western Chagos Archipelago; (c) Nosy Be, Madagascar. Data represent deployments of autonomous recorders from 24 November to 31 December 2011 and 1 January to 20 October 2012 off Oman, 4 yr of CTBTO data during January through December 2010, 2011, 2012, and 2013 from the Chagos Archipelago (from the Diego Garcia North recorder), and deployments of autonomous recorders from 1 January to 31 December for 2017 and 2018 off Madagascar; grey bars represent hours and days of no data before, between, and after deployments in Oman and Madagascar. All data are aligned so that each histogram represents a complete year, despite different timing of effort. For each day, bars represent the number of hours in which whale song was detected based upon a manual browse of spectrographic data from 0 to $60 \mathrm{~Hz}$ displayed frequency band, and hourly detections are stratified based on whether 1, 2, or 3+ individuals were assessed to be visible on the spectrogram. Dates are given as mo/d/yr 
a) Oman - Hallaniyats Bay; November 2011 to October $2012 ; 17.40^{\circ} \mathrm{N}, 55.31^{\circ} \mathrm{E}$
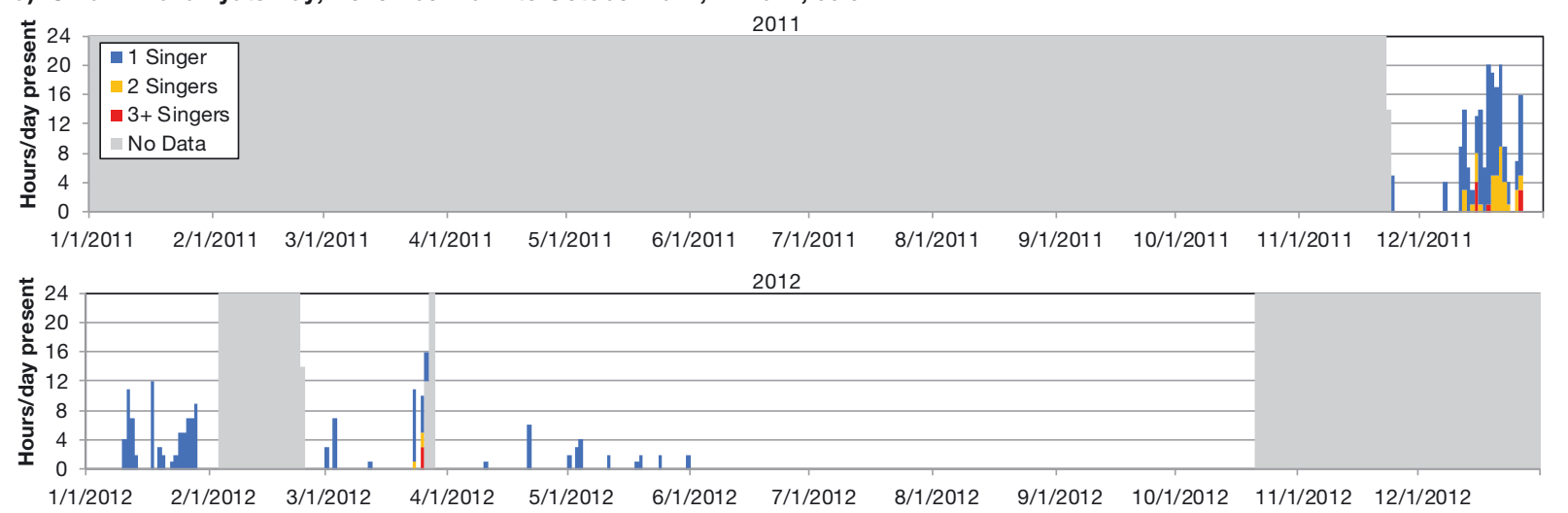

b) West Chagos Archipelago - Diego Garcia North; 2010, 2011, 2012 and 2013; 6.30 $\mathrm{S}, 71.00^{\circ} \mathrm{E}$
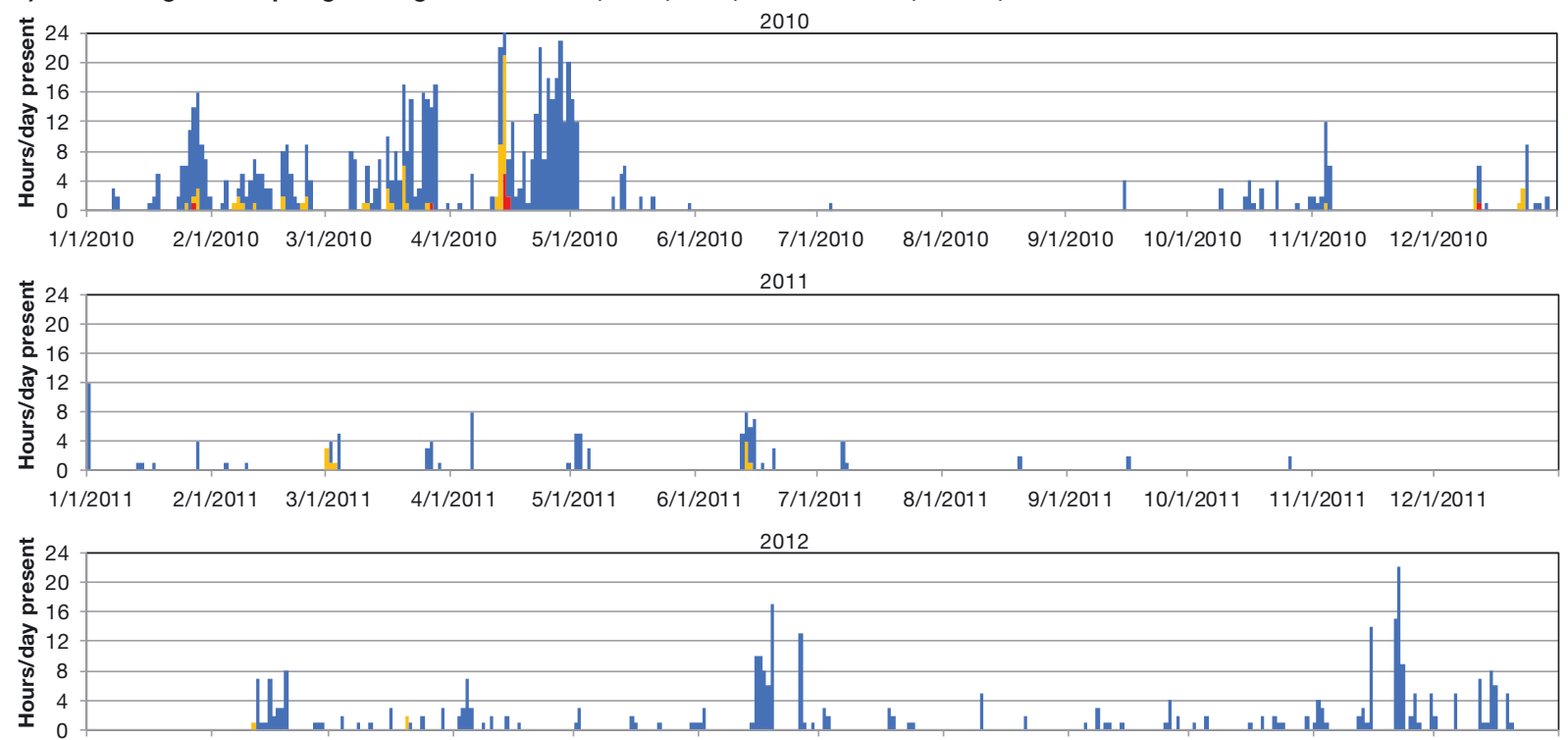

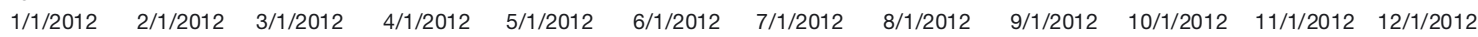

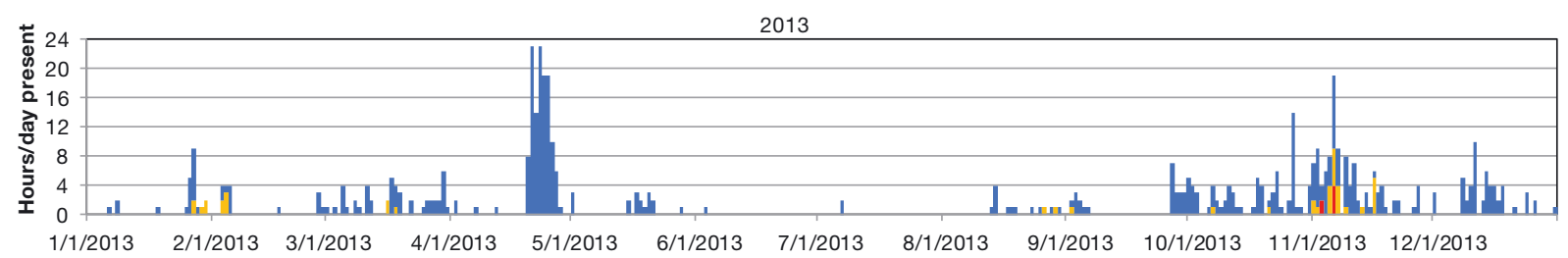

c) Madagascar - Nosy Be; 2017 and $2018 ; 13.28^{\circ} \mathrm{S}, 48.01^{\circ} \mathrm{E}$

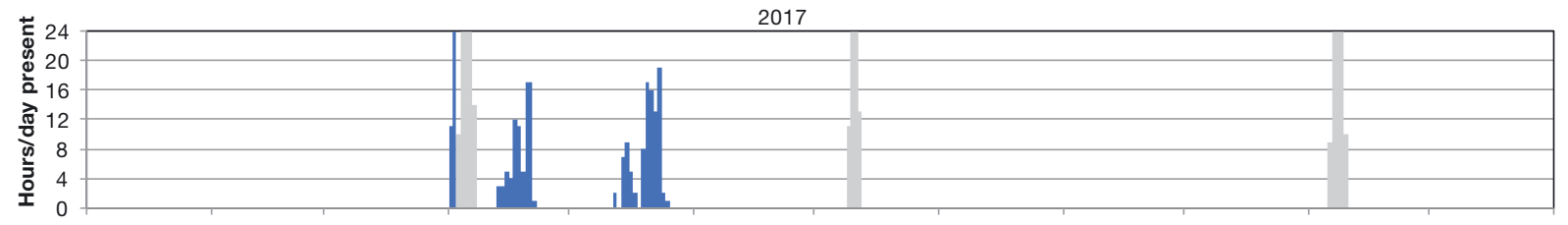

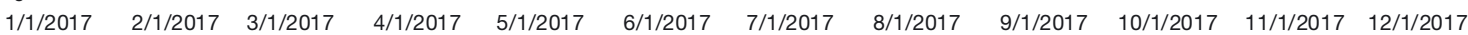

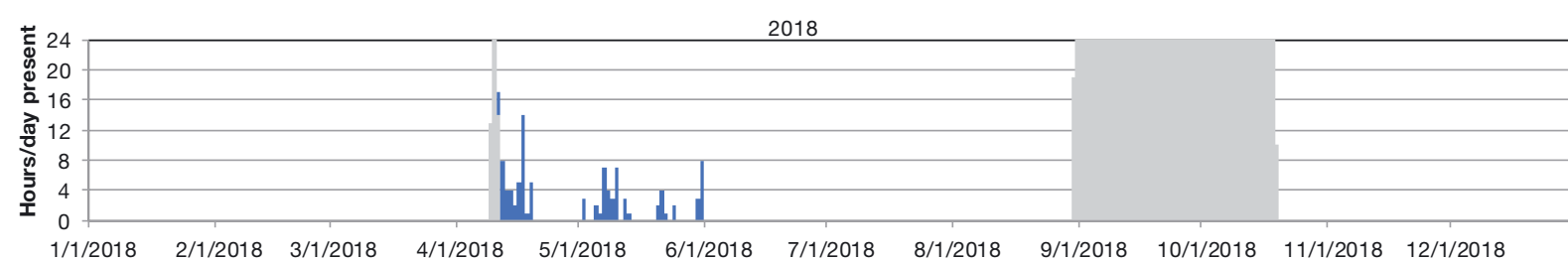



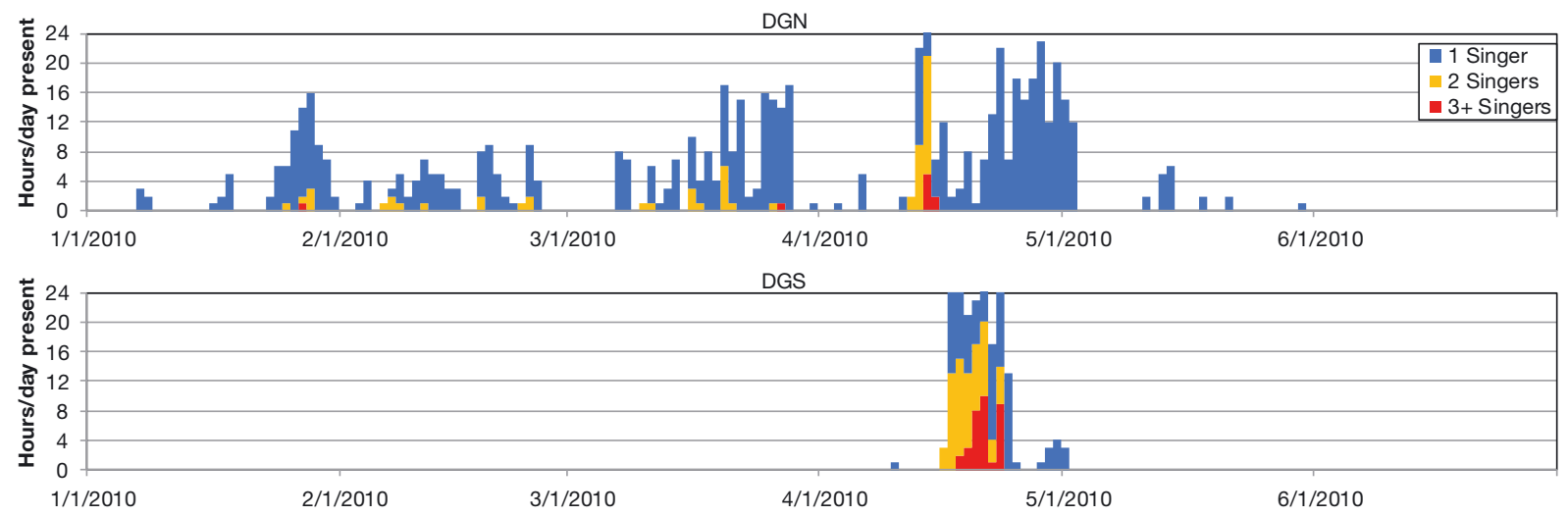

Fig. 7. Detail of hourly occurrence of the NWIO blue whale song-type at Chagos Archipelago, showing the first 6 mo of 2010 from Diego Garcia North (DGN, western Chagos) and Diego Garcia South (DGS, eastern Chagos), during the only period when the song was detected at DGS. Dates are given as mo/d/yr

its seasonality between the 2 years examined (Fig. 6c). In both 2017 and 2018, singing activity occurred in multiple distinct events of several days, each separated by periods of no detections ranging from 1 to 3 wk. Never was more than 1 singer evident at a time, and all detections had comparatively low SNR.

\section{DISCUSSION}

\subsection{Species attribution}

It is often difficult to definitively attribute a new baleen whale song-type to a species when based on recordings without associated visual sightings data. In this case, we believe that we can eliminate most Balaenoptera species based upon the known species diversity at our research sites, and the current understanding of baleen whale song characteristics. Fin, sei Balaenoptera borealis, Antarctic minke and common (dwarf) minke B. acutorostrata ssp. whales have not been confidently reported off Oman or in the Arabian Sea (Baldwin 2003, Minton et al. 2010), and their known vocal repertoires are distinctly different from this novel song-type (Watkins et al. 1987, Gedamke et al. 2001, Calderan et al. 2014, Risch et al. 2014). Sightings of Omura's whale B. omurai have not yet been reported in the Arabian Sea and appear not to be among sightings of balaenopterids off Oman (Minton et al. 2010), although a stranding has been reported off Iran (Ranjbar et al. 2016). Omura's whale song has now been described for several locations from the mid-equatorial Atlantic to the Western Indian Ocean to the northwest coast of Australia, with consistent features across this range that are stereotyped and distinctly different from the novel songtype we describe here (Cerchio et al. 2015, 2019,
Moreira et al. in press). Moreover, the stereotypical Omura's whale song was never detected off Oman in these recordings and was only rarely heard in deep water off Madagascar (being primarily heard in shallow shelf waters; Cerchio et al. 2015, 2018); therefore Omura's whales can safely be eliminated as a candidate species.

This assessment leaves 2 feasible candidate species as the source of this song, blue whales and Bryde's whales. Both species have been documented during boat surveys conducted off Oman in Hallaniyats Bay between 2001 and 2019, including in February and March 2012 when $22 \mathrm{~d}$ (170 h) of boat effort were conducted during the acoustic recording that documented the song (Minton et al. 2010, Willson et al. 2019, Oman Cetacean Database unpublished data; Fig. 8). Comparing the location of visual sightings with the temporal occurrence of recorded songs at stationary recording sites off Oman provides good circumstantial evidence for species attribution. When considering only days in 2012 when the novel songtype was recorded, there were balaenopterid sightings on 2 occasions that were near-concurrent with recordings of song. First, moderate to low SNR song (rating $\mathrm{B}, \mathrm{C}$, or $\mathrm{D}$ ) was recorded during a $2 \mathrm{~h}$ period on the evening of 1 March and during 6 daytime hours on 3 March, although there were no balaenopterid sightings during boat surveys on those 2 days ( 8 and $9 \mathrm{~h}$ of effort, respectively). A single Bryde's whale was sighted $20 \mathrm{~km}$ to the north on $2 \mathrm{March}_{\text {; }}$ however, this sighting did not correspond with concurrent detections of song, and as the only Bryde's whale sighting during March, it is not considered a strong candidate for species attribution. Conversely, there was a period of extensive singing (of the novel song-type) from 23 to 26 March, including a high SNR (rating A or B) chorus of more than 2 singers 


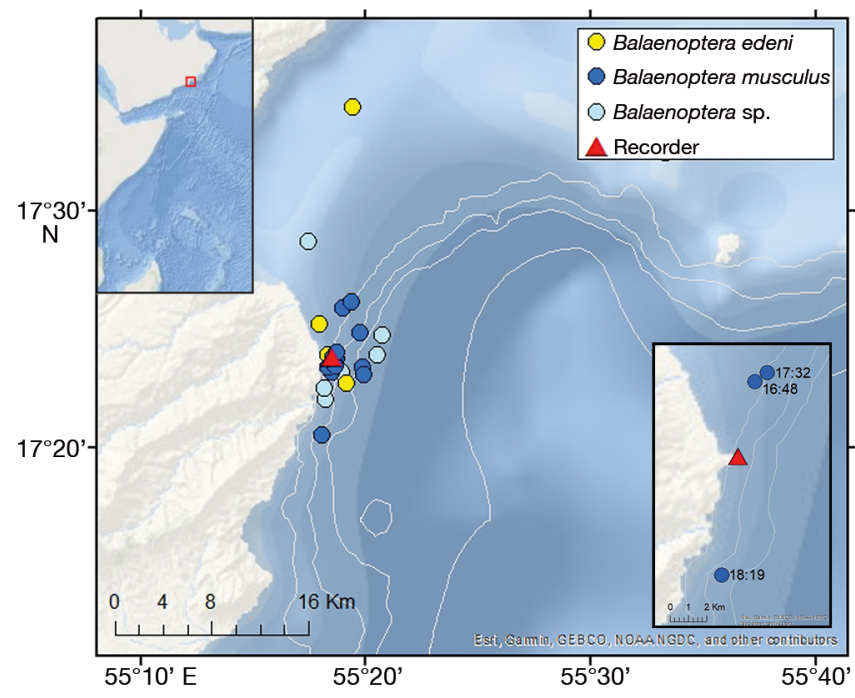

Fig. 8. Positions of blue whale and Bryde's whale sightings relative to the position of the Oman recorder site (Hallaniyats Bay) during surveys from 2004 to 2019, with top inset indicating location of the site in the Western Indian Ocean. Bottom inset detail: positions of a blue whale sighting on 26 March 2012, when there was high SNR blue whale song recorded prior to the recorder being recovered at 11:35 $\mathrm{h}$ local time; that afternoon at 16:48 h, a blue whale was sighted $4 \mathrm{~km}$ north of the recorder and was followed $10 \mathrm{~km}$ south until 18:19 h

during a $3.5 \mathrm{~h}$ period on the morning of 25 March, and high SNR song (rating A or B) during $4.5 \mathrm{~h}$ on the morning of $26 \mathrm{March}$, just prior to the recovery of the recorder. On 26-27 March, 3 blue whale sightings were made in the vicinity of the recorder position. The recorder was recovered on the morning of 26 March at 11:35 h local time, during a particularly high SNR sequence of song; approximately $5 \mathrm{~h}$ later that afternoon, at 16:48 $\mathrm{h}$ and again at 17:32 $\mathrm{h}$, the survey boat identified an individual blue whale $4 \mathrm{~km}$ to the north-northeast of the recorder site. This individual traveled southward to a point $6.2 \mathrm{~km}$ south of the recorder during a $44 \mathrm{~min}$ period (Fig. 8 inset). Although it is unfortunate that the recorder was not in the water during the observation, given the short period between the recording and observation, we consider this direct evidence of a blue whale being in the vicinity of the recorder during singing activity when no other baleen whales were sighted.

Off Madagascar, Bryde's whales have never been documented off the northwest coast study region despite extensive effort working with medium-sized balaenopterids (Omura's whales), surveying inshore and offshore waters, and passive acoustic monitoring in shallow and deep water (Cerchio et al. 2015, 2018, 2019); however, Bryde's whales are known to occur regionally in the Southwest Indian Ocean far to the south of Madagascar on the Madagascar Ridge (Best 2001). Conversely, blue whale song was detected extensively during passive acoustic monitoring off northwest Madagascar, including 3 different song-types (Antarctic, SWIO/Madagascar, and NIO/Sri Lanka) representing 3 separate populations in addition to the novel song-type recorded off Oman and Chagos (Cerchio et al. 2018); therefore, it is clear that this region is habitat for overlapping blue whale populations.

In addition to visual sighting evidence indicating the potential source of an acoustic signal, the structure of a vocalization can be a good indicator of species attribution when considered in the context of the known vocal repertoires of the candidate species. In this case, the features of the described song-type are much more congruent with identified song-types of blue whales (McDonald et al. 2006) as compared to Bryde's whales (Oleson et al. 2003, Heimlich et al. 2004, Helble et al. 2016). The most salient acoustic attributes of all known blue whale song-types that match the attributes of the song-type reported here include: songs composed of regularly spaced repetitions of a single phrase-type; phrases composed of 2-4 stereotyped, low-frequency sound units in the ca. $15-50 \mathrm{~Hz}$ band, with units containing frequencymodulated tonal components that transition to amplitude-modulated components; and unit durations in excess of $10 \mathrm{~s}$, phrase durations in excess of $30 \mathrm{~s}$, and repetition rates of phrases that are relatively short, such that the phrase interval is on the order of only 2-3 times the phrase duration (McDonald et al. 2006). Existing knowledge of Bryde's whale vocal repertoires from the eastern tropical Pacific, Gulf of California, southern Caribbean, and Hawaii include sequences of stereotyped vocalizations that could be considered song (Oleson et al. 2003, Heimlich et al. 2004, Helble et al. 2016), although these authors did not label them as such. For each of the repetitive vocalizations described for Bryde's whales, there are salient attributes that are distinctly different from those described for blue whales: vocal sequences are composed of regularly spaced repetitions of a single vocalization, or unit-type; units tend to be much shorter, primarily $<3 \mathrm{~s}$ without long tonal components; sequences of units have comparatively longer repetition rates (long intervals), ranging from 2 to $6 \mathrm{~min}$, so that the interval is on the order of 40-100 times the unit duration (Oleson et al. 2003, Heimlich et al. 2004, Helble et al. 2016). Putative vocalizations reported for Gulf of Mexico Bryde's whales (Rice et al. 2014) represent an exception to this pattern among other Bryde's whale populations; however, their vocalizations also appear distinctly different 
from blue whale songs. Moreover, new evidence indicates that the Gulf of Mexico population represents the possibly species-level divergence of a distinct lineage that does not occur in the Indian Ocean (Rosel \& Wilcox 2014, M. Leslie pers. comm.). With this understanding, the novel song-type reported here would represent an extreme outlier among the stereotyped repetitive vocalizations attributed to Bryde's whales, as compared to a blue whale songtype, for which it matches documented unit and phrase structure for populations worldwide. Given the acoustic attributes of the new song-type reported here, and the documented close proximity of a blue whale to our recorder off Oman when these songs were recorded, we conclude that these songs were almost certainly produced by a blue whale.

\subsection{Implications for blue whale population structure in the Indian Ocean}

Assuming this is a correct species attribution, these observations raise several implications and questions in regard to our understanding of population structure and definition of stocks of blue whales in the Indian Ocean. Different song-types have been used to distinguish between populations of blue whales in the Indian Ocean as well as globally. Given that this song-type has not been reported before, the presence of this song across a large geographic region indicates the likely existence of a previously undefined population of blue whales in the Western Indian Ocean. This is of particular consequence to the interpretation of existing whaling data, sightings data, and acoustic data. The northern Indian Ocean population of blue whales is currently considered to be acoustically defined by the 'Sri Lanka' or 'NIO' song-type; however, our results indicate that there are at least 2 blue whale acoustic populations that range into the northern Indian Ocean. Furthermore, analyses of the Oman acoustic data did not reveal any occurrence of the Sri Lanka song-type. Given that this novel song-type has not been previously reported in studies that documented the Sri Lanka song-type, and that no Sri Lanka song-types were detected in our analysis of the data off Oman, there may be a longitudinal division of these populations between (1) the Arabian Sea/general Western Indian Ocean, and (2) Sri Lanka/Bay of Bengal/general central Indian Ocean. We propose that this novel song be given the label 'NWIO' (for northwest Indian Ocean) song-type, in keeping with regional naming conventions intro- duced by McDonald et al. (2006), since it is the only song-type currently documented off Oman or in the western Arabian Sea.

It is worth emphasizing here that the only published evidence of the Sri Lanka song-type in the Northern Hemisphere comes from limited boat-based recordings off the eastern coast of Sri Lanka during February to April 1984, and May 1985 (Alling \& Payne 1985, Alling et al. 1991). The Sri Lanka songtype has been most extensively documented off the equatorial Chagos Archipelago and other sites throughout the Southern Hemisphere (Stafford et al. 2011, Samaran et al. 2013, Leroy et al. 2018b). To our knowledge, prior to this study there was a complete absence of acoustic data from the Arabian Sea, and thus no confirmation of any song-type. Therefore, the attribution of Arabian Sea sightings and whaling catches to the Sri Lanka acoustic population by various authors and the International Whaling Commission Scientific Committee (Branch et al. 2007b, 2019, Anderson et al. 2012, Ilangakoon \& Sathasivam 2012) has been based entirely upon the assumption that there was/is a single population in the northern Indian Ocean. There is relatively extensive documentation of blue whales on the eastern, southern, and western sides of Sri Lanka (Anderson et al. 2012, Ilangakoon \& Sathasivam 2012, de Vos et al. 2014, Randage et al. 2014), but currently no published long-term acoustic monitoring from Sri Lanka, or any other location in the eastern Arabian Sea. Therefore, it is an open question as to whether the blue whales in the eastern Arabian Sea, including off the west coast of Sri Lanka, belong to the 'Sri Lanka' acoustic population, or to the new NWIO acoustic population described here. We note that Anderson et al. (2012, their Fig. 5) indicated inverse peak occurrence of blue whale sightings off west Sri Lanka (JuneAugust) and northeast/south Sri Lanka (ca. JanuaryMay for northeast, November-April for south), which may represent the co-occurrence of 2 populations with varying temporal distributions. It is noteworthy that the seasonal peak occurrence of blue whale visual sightings off western Sri Lanka is concurrent with the apparent seasonal absence of the NWIO song-type off Oman (June-October), whereas the peaks off northeast and south Sri Lanka (during which time the Sri Lanka song-type was recorded, Alling et al. 1991) are concurrent with the presence of the NWIO song-type off Oman (December-May). Although speculative at this point, this pattern is congruent with a hypothesis that these 2 acoustic populations may have overlapping but temporally asynchronous distributions around Sri Lanka. 
The patterns of documented presence in this study suggest that the NWIO song-type was detected more extensively and during a more extended period of the year off Oman than off Madagascar, but most extensively throughout the year off western Chagos. It is important to consider here the differences in propagation characteristics at each site and the likely ranges at which songs were detected. The deeper recorders deployed off Chagos and Madagascar had an acoustically unobstructed 'view' of the deepwater soundscape and likely detected signals at much greater distance than the shallow-water recorders perched on the top of the shelf break off Oman. Off Madagascar, there was much more extensive documentation and higher SNR detections of other lowfrequency baleen whale songs in the same data set, including Antarctic and Madagascar pygmy blue whales, and fin whales (Cerchio et al. 2018). Therefore, we surmise that the detections of the NWIO song-type off Madagascar were likely isolated events of relatively distant single animals. The recorders off Chagos likely had the furthest detection range of all 3 sites, since they were positioned in the SOFAR channel; as an example, Samaran et al. (2010b) estimated a maximum detection range of $150 \mathrm{~km}$ for pygmy blue whale song from the CTBTO Crozet Island recorders (also suspended in the SOFAR channel, though at $46.2^{\circ} \mathrm{S}$ ). This may in part explain the more widely distributed occurrence of the song off west Chagos compared to the other sites. Conversely, off Oman we expect extensive propagation loss of signals originating in deep water before they were detected on the shallow-water shelf recorder. Given the generally pelagic distribution of blue whales and that all observed sightings of blue whales off the Oman site were in deep water off the shelf break (Willson et al. 2019; see above), the low SNR detections likely represent relatively close individuals singing off the shelf in nearby deep water. Therefore, the observed distribution of detections off Oman may be a substantial underestimate of presence. Furthermore, given the presence of choruses of song on several days despite the poor propagation characteristics, it is possible that had monitoring been conducted off the shelf in deep water, much more extensive presence between December and June may have been documented.

Irrespective of this caveat, the data indicate that the NWIO acoustic population is not limited to the northern Indian Ocean, and like other blue whale populations, is capable of extensive movements. Moreover, the sampling presented here is limited to only these 3 sites, and it is possible that exploration of recordings from other sites in the Indian Ocean may reveal a wider distribution and range. However, the limited presence in the Madagascar data suggests that this population may be more associated with the northern Indian Ocean, and only an occasional visitor, possibly at the southern extreme of its range, in the southwest Indian Ocean and the Mozambique Channel. The variable presence off the Chagos throughout the year may represent movements south and north at different periods; the data from 2010 and 2013 have a minor indication of some bimodal seasonality that could be indicative of migratory movement, but it is not well-defined and not consistent across all monitored years.

Anderson et al. (2012) proposed a hypothesis for the migratory movements of blue whales in the northern Indian Ocean, striving to interpret all existing spatiotemporal data of sightings, catches, strandings, and acoustic records. Predictions of this migration hypothesis were based on an assumption that the data represented a single population, which was reasonable given the understanding at the time. However, our results indicate that there are likely at least 2 populations with potentially distinct or partially overlapping distributions. Anderson et al. (2012) predicted occurrence off the Arabian Peninsula during the southwest monsoons, May to October; however, the NWIO song is almost entirely absent in the Oman data during that time, with the exception of scattered infrequent detections in May. Without a clear understanding of singing seasonality and spatiotemporal variation, absence of song does not necessarily indicate absence of animals, but within our data from all sites, some singing activity occurred throughout the year and was recorded off Chagos when none was recorded off Oman (Figs. 6 \& 9). Therefore, we have reason to believe that in this case, song may be considered a reasonable indicator of presence/absence. Moreover, Anderson et al. (2012) suggested that the population disperses widely during the northeast monsoons, December-March, migrating eastwards north of the Maldives and south of Sri Lanka during December-January; however, this is when the occurrence of blue whale song off Oman is at its peak. These contradictions may result from the interpretation of the existing data by Anderson et al. (2012) under the assumption of a single northern Indian Ocean population.

Inasmuch as the repeated seasonal occurrence of song can represent movements of a population, the strongly seasonal occurrence of the NWIO song-type off Madagascar during April-May (in 2017 and 2018, Fig. 6C) would suggest a possible southerly move- 

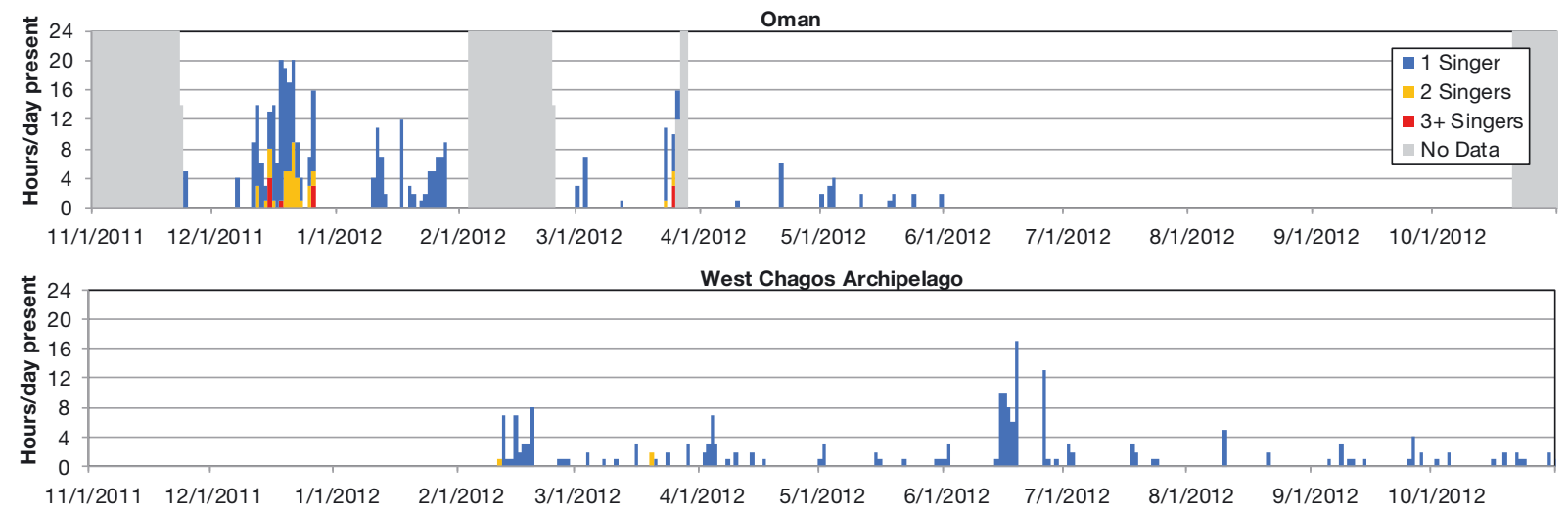

Fig. 9. Detail of hourly occurrence of detections of the NWIO blue whale song-type during the period of concurrent data collection at Hallaniyats Bay, Oman, and western Chagos Archipelago, November 2011 through October 2012. Dates are given as $\mathrm{mo} / \mathrm{d} / \mathrm{yr}$

ment out of the Arabian Sea; the occurrence of the song-type off the western Chagos Archipelago further supports this possible scenario, but with less clear seasonality and strong variation among years. Focusing exclusively on the acoustic data collected concurrently during November 2011 through October 2012 off Oman and Chagos, the observed temporal distribution of song detections is consistent with presence in the Arabian Sea during the early period of the northeast monsoon, when it is absent off the Chagos, followed by movement south into the region west of the Chagos starting in February, and being absent from Oman by June (Fig. 9). The variability of occurrence off the Chagos across the 4 years examined suggests that movement patterns likely do not follow a regimented seasonal migratory cycle (i.e. long-distance latitudinal migration associated with temporal separation of feeding and breeding ecology). Rather, the movements of this and other blue whale populations may reflect the complex dynamic processes in the Indian Ocean, with population distribution shifts dependent on yearly variable changes in productivity. Interannual variability has been documented in the northern Indian Ocean and is hypothesized to drive variation in blue whale temporal distribution off the Maldives and Sri Lanka (Ballance et al. 2001, de Vos et al. 2014). Redfern et al. (2017) predicted that suitable blue whale habitat should exist off the Arabian Peninsula and the Gulf of Aden in both monsoon seasons, applying generalized additive models developed with extensive datasets from the eastern Pacific Ocean, and remote sensing data of environmental variables in the northern Indian Ocean, but averaged across 2 decades without accounting for interannual variability. Therefore, it is possible that the single year of monitoring off Oman does not capture the full seasonal variability in blue whale distribution, and that the multi-year patterns off Chagos are a reflection of interannual variability in environmental conditions.

The near absence of the NWIO blue whale song in data from the eastern side of the Chagos (DGS recorder) is striking in comparison to its geographically widespread presence in the Western Indian Ocean from Oman to Madagascar. Since the Chagos Bank acts as an acoustic barrier between the DGN and DGS recorders (Pulli \& Upton 2001), it appears that the Chagos (roughly $70^{\circ} \mathrm{E}$ ) may represent an eastern boundary for the population, suggesting a truly Western Indian Ocean distribution. This is in contrast to the Sri Lanka acoustic population, which is heard more broadly on both the west (DGN) and east (DGS) side of the Chagos (Stafford et al. 2011, Samaran et al. 2013) although throughout a broader range of months on the east side (see Samaran et al. 2013, their Fig. 5b). Moreover, the Sri Lanka acoustic population appears to have a more central Indian Ocean distribution, documented more extensively on recorders east of $70^{\circ} \mathrm{E}$ but far less frequently to the west of $70^{\circ} \mathrm{E}$ (eastern sites DGN, DGS, NEAMS, SWAMS as compared to western sites MAD, CROZET, SSEIR, NCRO, WKER, as defined by Samaran et al. 2013 and Leroy et al. 2018b). Consequently, we recommend that the Sri Lanka song-type no longer be referred to as the 'NIO' (North Indian Ocean) song-type, but rather the as the 'CIO' (Central Indian Ocean) songtype, reflecting its currently described distribution.

\subsection{Implications for conservation of blue whales in the Arabian Sea}

The presence of this acoustic population off the coast of Oman during the boreal winter/spring, from 
November through May, is congruent with the timing of illegal Soviet whaling catches in the region (Mikhalev 1996, 2000) and visual observations off Oman (Minton et al. 2010, Willson et al. 2019). Soviet catches of 1294 blue whales in the Arabian Sea occurred during 4 whaling seasons from OctoberDecember 1963-1967 (Mikhalev 1996, 2000), with the predominant catches being off the Arabian Peninsula during November (see Fig. 2). Although we do not have acoustic data from Oman during November, the peak occurrence of the NWIO song during December leads to the conclusion that the population hunted by Soviet whalers in the Gulf of Aden and the western Arabian Sea was very likely the NWIO acoustic population, not the Sri Lanka/CIO acoustic population. The general assumption up until now has been that all whales taken in the northern Indian Ocean came from the Sri Lanka acoustic population (Branch et al. 2007b, 2019). Since blue whale acoustic populations are generally considered to be synonymous with biological populations (McDonald et al. 2006, Branch et al. 2007b), we now conclude that at least some if not most of these catches in the northern Indian Ocean came from a distinct population that has not been previously accounted for. This discovery has major consequences for the conservation status of northern Indian Ocean blue whales. Given the size of the Soviet catch within such a relatively restricted region, it is conceivable that the population was severely depleted. A very small population size, in combination with the lack of recording effort in the Arabian Sea, may explain why this songtype has gone undetected for so long.

Arabian Sea humpback whales are a genetically distinct and highly diverged population (Pomilla et al. 2014) that were also severely impacted by Soviet whaling operations (Mikhalev 1997). They currently are estimated to have a very low population abundance, with likely fewer than 100 animals and a point estimate of 82 individuals (95\% CI 60-111), leading to their classification as Endangered according to the IUCN Red List of Threatened Species (Minton et al. 2008, 2011). The Soviet whalers took 242 humpback whales off the coasts of Oman, Pakistan, and India, of a population they estimated to be on the order of 400 individuals (Mikhalev 1997). Given the size of the blue whale catch, the source population was clearly much larger than the humpback whale population; however, it seems feasible, if not likely, that the blue whale population was reduced to an equally small fraction of the original population size, with total numbers of catches decreasing from 1060, during the $1963 / 64$ and 1964/1965 expeditions, to 234 during the 1965/66 and 1966/67 expeditions (Mikhalev 1996, 2000). It is worth noting that blue whale sightings off Oman are very rare (Baldwin 2003, Minton et al. 2010), which may be related to distribution and sighting effort, but may also be a reflection of very low numbers of individuals in the current population.

Currently there is some debate and difference of opinion regarding the taxonomic status of blue whales in the northern Indian Ocean, and thus it remains unresolved. If in fact a northern Indian Ocean population is recognized as a separate subspecies, its threatened conservation status would be of greater consequence than if it was considered a population of B. musculus brevicauda. Rice (1998) recognized the subspecies $B$. m. indica Blyth, 1859, based upon the description of $B$. indica from a specimen examined by Blyth in the northeastern Bay of Bengal. Rice (1998) assigned the subspecies B. m. indica to all blue whales thought to occur year-round in the northern Indian Ocean, including the Gulf of Aden, Persian/ Arabian Gulf, Arabian Sea, coasts of Pakistan and India, and Sri Lanka, despite the type specimen coming from Myanmar. Conversely, Branch \& Mikhalev (2008) found little support for subspecies classification of northern Indian Ocean blue whales (to distinguish them from B. m. brevicauda), based on length at maturity data from the illegal Soviet pelagic catches, and noted that different subspecies should be distinct based upon geographic distribution as well as attributes of 'morphology, genetics or behavior' (Branch et al. 2007a). However, evidence for behavioral and ecological differentiation may exist in the Soviet whaling fetal length data. Mikhalev (1996, 2000) reported differences in the size of fetuses among the separate regions of Soviet catches, separating the fetus data into 3 categories of (1) early stage of development, size not determined, (2) small size, 40-326 cm, and (3) large size, $>340 \mathrm{~cm}$. He reported the Seychelles-Equator catches were entirely early development $(\mathrm{n}=5)$ and small size $(\mathrm{n}=39$, range $84-326 \mathrm{~cm}$ ), congruent with a Southern Hemisphere breeding cycle. Conversely, the northern Indian Ocean catches were more evenly spread between early development $(\mathrm{n}=20)$, small $(\mathrm{n}=23$, range $40-315 \mathrm{~cm}$ ) and large $(\mathrm{n}=42$, range $343-$ $680 \mathrm{~cm}$ ) sizes, particularly for the Gulf of Aden/Oman and Lakshadweep/Maldives catch regions. Mikhalev $(1996,2000)$ interpreted these data as evidence of 2 peaks of reproduction offset by 6 mo (with breeding season peaks in both May and November), and thereby coinciding with both Southern and Northern Hemisphere cycles. However, closer examination of Mikhalev (1996, his Fig. 8; and the identical Fig. 4 in 
Mikhalev 2000), suggests not a bimodal distribution of fetal length, but rather a more continuous distribution of fetal lengths from near $0 \mathrm{~cm}$ (early development) to $680 \mathrm{~cm}$ (prenatal or full term). This could imply aseasonal reproduction or a protracted period of conception throughout the year, as also noted by Branch et al. (2019). If this population does not conform to either a strictly Northern or Southern Hemisphere breeding cycle, but rather conceives throughout the year (or during biannual peaks as proposed by Mikhalev 1996), this could represent a distinct and unique life history pattern that would reinforce a subspecies classification of the blue whales occurring in the Arabian Sea. The relevant point to this discussion is that the whales captured off Oman, and thus belonging to the NWIO acoustic population, would belong to the putative northern Indian Ocean subspecies. Irrespective of decisions on nomenclature (i.e. B. m. indica), if there is a separate subspecies in the northern Indian Ocean, then based upon geographic and life history parameter distinctiveness, it may more likely include the NWIO acoustic population than the Sri Lanka/CIO acoustic population. Future work is needed to address interactions between populations in the northern Indian Ocean and the taxonomic status of the Sri Lanka/CIO acoustic population, but certainly the NWIO acoustic population would be included in the subspecies, thereby emphasizing the importance of better understanding the conservation status of this population.

Our observation and initial assessment of this new song-type/acoustic population, and thus potentially a distinct biological population of blue whales in the northwestern Indian Ocean, should lead to dedicated research to better understand it, particularly in light of the conservation implications. Blue whales are considered Endangered globally (Cooke 2018), and cetaceans in the Indian Ocean are known to be under threat from increasing fisheries activity (Anderson et al. 2020) as well as shipping, oil and gas exploration and production, and coastal development. Blue whales are known to be particularly vulnerable to ship strikes (e.g. McKenna et al. 2015, Rockwood et al. 2017), a risk which is likely to increase with the construction and expansion of ports on the coasts of Oman and Pakistan, among other places. Efforts to conduct deep-water acoustic monitoring off the coast of Oman are critical to validate these initial observations, and will allow definitive attribution to species when combined with boat-based surveys and recordings in the vicinity of blue whales. Additional acoustic monitoring should be conducted throughout the Arabian Sea, particularly off the coasts of Pakistan and northern India in the region of the former Soviet whaling catches in the northeastern Arabian Sea. This would help assess if these clusters of catches belonged to the same NWIO acoustic population as documented off Oman; recent observations of blue whales confirm that a population continues to utilize this habitat in this region of the Soviet catches (Sutaria et al. 2016, 2017, Moazzam \& Nawaz 2019).

Acoustic monitoring should also be conducted off southern India and Sri Lanka to help establish the respective spatiotemporal distributions of the Sri Lanka/CIO and the NWIO song-type acoustic populations. Existing acoustic datasets throughout the Indian Ocean should be evaluated for the presence of the NWIO song-type, particularly in datasets for which only automated detection of previously described song-types has been targeted (i.e. for which lack of manual browsing would have hindered discovery of an unexpected or previously undescribed vocalization). Current data and discussions on the population structure and conservation status of Indian Ocean blue whales (e.g. Branch et al. 2019) should be reconsidered in light of the possibility that at least 2 distinct populations may range in the northern Indian Ocean. Most importantly, efforts should be made to assess the genetic identity and conservation status of blue whales in the Arabian Sea (including the Persian/Arabian Gulf, Gulf of Oman, Arabian Sea, and Gulf of Aden) and the wider Western Indian Ocean, particularly given the following key conclusions: (1) that there now appears to exist a distinct population (the NWIO acoustic population) that has gone unrecognized due to being conflated with another more widespread population (the Sri Lanka/ CIO acoustic population); (2) that the NWIO acoustic population was likely the main target of the extensive illegal Soviet catches; (3) that this population may be a candidate as a separate subspecies given current data on distribution and reproductive timing; and (4) that it is potentially severely depleted as a result of the intensive illegal whaling within its restricted range in the 1960 s, and therefore is in need of critical conservation actions similar to those being proposed for the Arabian Sea population of humpback whales (CMS 2017, IWC 2020).

Acknowledgements. We are grateful to the Environment Agency \& Ministry of Agriculture and Fisheries Wealth, Oman, for participation of staff in field activities and issuing of permits to conduct field research. We thank all staff at the Environment Society of Oman (www.eso.org.om) and Five Oceans Environmental Services LLC, through whom the field project is run, and the network of volunteers for continued support of whale and dolphin research and con- 
servation in Oman. Cherry Allison provided the IWC individual catch database Vesion 6.1, 18 July 2016, and Trevor Branch provided data on sightings of blue whales in the Indian Ocean depicted in Fig. 2. Sincere thanks are given for financial support for Oman fieldwork provided by Renaissance Services S.A.O.G since 2011, and funding for analysis provided by Shell-Oman in 2015 and by Five Oceans Environmental Services in 2019. In Madagascar, equipment was made available by funding initially provided by the US Marine Mammal Commission, with additional equipment support from Sofie van Parijs, and a grant from the International Whaling Commission Scientific Committee. Research authorization in Madagascar was obtained from partners Centre National de Recherches Océanographiques, Nosy Be, and L'Institut Halieutique et des Sciences Marines de l'Université de Toliara. Access to the hydroacoustic data from the CTBTO hydrophone station HA08 at Chagos Archipelago was made available to T.L.R. through a virtual Data Exploitation Centre (vDEC) Contract (https:// www.ctbto.org/specials/vdec/) with the University of New South Wales, School of BEES, and the CTBTO Preparatory Commission for the project entitled 'Blue Whales in the Southern Hemisphere'. The views expressed herein are those of the authors and do not necessarily reflect the views of the CTBT Preparatory Commission.

\section{LITERATURE CITED}

Alling A, Payne R (1985) Song of the Indian Ocean blue whale, Balaenoptera musculus spp. Report of the Long Term Research Institute. www.pcrf.org/bluewhalepaper.pdf

Alling A, Dorsey EM, Gordon JCD (1991) Blue whales (Balaenoptera musculus) off the northeast coast of Sri Lanka: distribution, feeding and individual identification. In: Leatherwood S, Donovan GP (eds) Cetaceans and cetacean research in the Indian Ocean sanctuary. Marine Mammal Technical Report No. 3. UNEP, Nairobi, p 247-258

Anderson RC, Branch TA, Alagiyawadu A, Baldwin R, Marsac F (2012) Seasonal distribution, movements and taxonomic status of blue whales (Balaenoptera musculus) in the northern Indian Ocean. J Cetacean Res Manag 12:203-218

Anderson RC, Herrera M, Ilangakoon AD, Koya KM, Moazzam M, Mustika PL, Sutaria DN (2020) Cetacean bycatch in Indian Ocean tuna gillnet fisheries. Endang Species Res 41:39-53

Baldwin RM (2003) Whales and dolphins of Arabia. Mazoon Printing Press, Muscat

Ballance LT, Anderson RC, Pitman RL, Stafford K, Shaan A, Waheed Z, Brownell Jr RL (2001) Cetacean sightings around the Republic of the Maldives, April 1998. J Cetacean Res Manag 3:213-218

Barber R, Sikora I, Nimak-Wood M (2016) Blue whales Balaenoptera musculus in offshore waters of Kenya. Afr J Mar Sci 38:279-284

Best PB (2001) Distribution and population separation of Bryde's whale Balaenoptera edeni off southern Africa. Mar Ecol Prog Ser 220:277-289

Bioacoustics Research Program (2014) Raven Pro: interactive sound analysis software (Version 1.5). The Cornell Lab of Ornithology, Ithaca, NY. http://ravensound software.com/

Branch TA, Mikhalev YA (2008) Regional differences in length at sexual maturity for female blue whales based on recovered Soviet whaling data. Mar Mamm Sci 24: 690-703

* Branch TA, Abubaker EMN, Mkango S, Butterworth DS (2007a) Separating southern blue whale subspecies based on length frequencies of sexually mature females. Mar Mamm Sci 23:803-833

Kranch TA, Stafford KM, Palacios DM, Allison C and others (2007b) Past and present distribution, densities and movements of blue whales Balaenoptera musculus in the Southern Hemisphere and northern Indian Ocean. Mamm Rev 37:116-175

* Branch TA, Mikhalev YA, Kato H (2009) Separating pygmy and Antarctic blue whales using long-forgotten ovarian data. Mar Mamm Sci 25:833-854

Branch TA, Monnahan CC, Širović A, Balcazar N and others (2019) Further analyses to separate pygmy blue whale catches by population. International Whaling Commission Scientific Committee Paper SC/68A/SH/15

Calderan S, Miller B, Collins K, Ensor P, Double M, Leaper R, Barlow J (2014) Low-frequency vocalizations of sei whales (Balaenoptera borealis) in the Southern Ocean. J Acoust Soc Am 136:EL418-EL423

Cerchio S, Collins T, Mashburn S, Clark C, Rosenbaum H (2010) Acoustic evidence of blue whales and other baleen whale vocalizations off northern Angola. International Whaling Commission Scientific Committee Paper $\mathrm{SC} / 62 / \mathrm{SH} / 13$

Cerchio S, Andrianantenaina B, Lindsay A, Rekdahl M, Andrianarivelo N, Rasoloarijao T (2015) Omura's whales (Balaenoptera omurai) in Northwest Madagascar: ecology, behaviour and conservation needs. R Soc Open Sci 2:150301

Cerchio S, Willson A, Muirhead C, Minton G and others (2016) Preliminary report on long-term detection of Arabian Sea humpback whale vocalizations off Oman. International Whaling Commission Scientific Committee Paper SC/66B/SH/

Cerchio S, Rasoloarijao T, Cholewiak D (2018) Acoustic monitoring of blue whales (Balaenoptera musculus) and other baleen whales in the Mozambique Channel off the northwest coast of Madagascar. International Whaling Commission Scientific Committee Paper SC/67B/SH/14

Cerchio S, Yamada T, Brownell RL Jr (2019) Global distribution of Omura's whales (Balaenoptera omurai) and assessment of range-wide threats. Front Mar Sci 6:67

CMS (Convention on Migratory Species) (2017) Concerted action for humpback whales (Megaptera novaeangliae) of the Arabian Sea. UNEP/CMS/Concerted Action 12.4. Adopted by the Conference of Parties at its $12^{\text {th }}$ Meeting. Convention on Migratory Species, Manila. https://www. cms.int/sites/default/files/document/cms_cop12_ca.12.4 _humpback-whales-arabian-sea_e.pdf

Cooke JG (2018) Balaenoptera musculus. The IUCN Red List of Threatened Species 2018. e.T2477A50226195. https://dx.doi.org/10.2305/IUCN.UK.2018-2.RLTS.T2478 A50349982.en (accessed 24 February 2019)

* De Vos A, Pattiaratchi CB, Harcourt RG (2014) Inter-annual variability in blue whale distribution off southern Sri Lanka between 2011 and 2012. J Mar Sci Eng 2:534-550

Gedamke J, Costa DP, Dunstan A (2001) Localization and visual verification of a complex minke whale vocalization. J Acoust Soc Am 109:3038-3047

*Hanson JA (2001) Initial analysis of data from the new Diego Garcia hydroacoustic station. Proc $23^{\text {rd }}$ Seis Res Sym, 
Jackson Hole, WY, p 12-25. https://www.ldeo.columbia.edu/res/pi/Monitoring/Doc/Srr_2001/Print/05-02.pdf

Heimlich SL, Nieukirk SL, Mellinger DK, Dziak R, Matsumoto H, Fowler M (2004) Bryde's whale (Balaenoptera edeni) sounds collected from autonomous hydrophones in the eastern tropical Pacific, 1999-2001. J Acoust Soc Am 116:2614

Helble TA, Henderson EE, Ierley GR, Martin SW (2016) Swim track kinematics and calling behavior attributed to Bryde's whales on the Navy's Pacific Missile Range Facility. J Acoust Soc Am 140:4170-4177

Ilangakoon AD, Sathasivam K (2012) The need for taxonomic investigations on Northern Indian Ocean blue whales (Balaenoptera musculus): implications of yearround occurrence off Sri Lanka and India. J Cetacean Res Manag 12:195-202

IWC (International Whaling Commission) (2020) Report of the Scientific Committee 2020. International Whaling Commission, Cambridge. https://archive.iwc.int/pages/ view.php?ref=17766\&k=

Keroy EC, Royer JY, Bonnel J, Samaran F (2018a) Long-term and seasonal changes of large whale call frequency in the southern Indian Ocean. J Geophys Res 123: 8568-8580

Leroy EC, Samaran F, Stafford KM, Bonnel J, Royer JY (2018b) Broad-scale study of the seasonal and geographic occurrence of blue and fin whales in the Southern Indian Ocean. Endang Species Res 37:289-300

Ljungblad DK, Clark CW, Shimada H (1998) Comparison of sounds attributed to pygmy blue whales (Balaenoptera musculus brevicauda) recorded south of the Madagascar Plateau and those attributed to 'true' blue whales (Balaenoptera musculus) recorded off Antarctica. Rep Int Whaling Comm 48:439-442

McDonald MA, Mesnick SL, Hildebrand JA (2006) Biogeographic characterization of blue whale song worldwide: using song to identify populations. J Cetacean Res Manag 8:55-65

McDonald MA, Hildebrand JA, Mesnick S (2009) Worldwide decline in tonal frequencies of blue whale songs. Endang Species Res 9:13-21

* McKenna MF, Calambokidis J, Oleson EM, Laist DW, Goldbogen JA (2015) Simultaneous tracking of blue whales and large ships demonstrates limited behavioral responses for avoiding collision. Endang Species Res 27: 219-232

Mikhalev YA (1996) Pygmy blue whales of the northernwestern Indian Ocean. International Whaling Commission Scientific Committee Paper SC/48/SH/30

Mikhalev YA (1997) Humpback whales Megaptera novaeangliae in the Arabian Sea. Mar Ecol Prog Ser 149:13-21

Mikhalev YA (2000) Whaling in the Arabian Sea by the whaling fleets Slava and Sovetskaya Ukraina. In: Yablokov AV, Zemsky VA (eds) Soviet whaling data [19491979]. Center for Russian Environmental Policy, Marine Mammal Council, Moscow, p 141-181

* Minton G, Collins T, Pomilla C, Findlay KP, Rosenbaum H, Baldwin R, Brownell Jr RL (2008) Megaptera novaeangliae (Arabian Sea subpopulation). The IUCN Red List of Threatened Species 2008. e.T132835A3464679. https://dx.doi.org/10.2305/IUCN.UK.2008.RLTS.T132835A 3464679.en (accessed on 13 January 2020)

Minton G, Collins TJQ, Findlay KP, Baldwin R (2010) Cetacean distribution in the coastal waters of the Sultanate of Oman. J Cetacean Res Manag 11:301-313
Minton G, Collins TJQ, Findlay KP, Ersts P, Rosenbaum HC, Berggren P, Baldwin RM (2011) Seasonal distribution, abundance, habitat use and population identity of humpback whales in Oman. J Cetacean Res Manag 3:185-198

Moazzam M, Nawaz R (2019) The distribution of whales in the northern Arabian Sea along the coast of Pakistan obtained through crew-based observer programmeresults of the 2018 fishing season. International Whaling Commission Scientific Committee Paper SC/68A/CMP/07

Moreira S, Weksler M, Sousa-Lima RS, Maia M and others (in press) Occurrence of Omura's whale, Balaenoptera omurai (Cetacea: Balaenopteridae), in the Equatorial Atlantic Ocean based on passive acoustic monitoring. J Mamm, doi:10.1093/jmammal/gyaa130

* Oleson EM, Barlow J, Gordon J, Rankin S, Hildebrand JA (2003) Low frequency calls of Bryde's whales. Mar Mamm Sci 19:407-419

*Pastene LA, Acevedo J, and Branch TA (2020) Morphometric analysis of Chilean blue whales and implications for their taxonomy. Mar Mamm Sci 36:116-135

Pomilla C, Amaral AR, Collins T, Minton G and others (2014) The world's most isolated and distinct whale population? Humpback whales of the Arabian Sea. PLOS ONE 9: e114162

* Pulli JJ, Upton ZM (2001) Hydroacoustic blockage at Diego Garcia: models and observations. Proc $23^{\text {rd }}$ Seis Res Symp, Jackson Hole, WY, p 45-54. https://www.ldeo. columbia.edu/res/pi/Monitoring/Doc/Srr_2001/Print/0506.pdf

Randage SM, Alling A, Currier K, Heywood E (2014) Review of the Sri Lanka blue whale (Balaenoptera musculus) with observations on its distribution in the shipping lane. J Cetacean Res Manag 14:43-49

* Ranjbar S, Dakhteh SMH, Van Waerebeek K (2016) Omura's whale Balaenoptera omurai stranding on Qeshm Island, Iran, Persian Gulf: further evidence for a wide (sub)tropical distribution. J Mar Biol Oceanogr 5:3

* Redfern JV, Moore TJ, Fiedler PC, de Vos A and others (2017) Predicting cetacean distributions in data-poor marine ecosystems. Divers Distrib 23:394-408

Rice AN, Palmer KJ, Tielens JT, Muirhead CA, Clark CW (2014) Potential Bryde's whale (Balaenoptera edeni) calls recorded in the northern Gulf of Mexico. J Acoust Soc Am 135:3066-3076

Rice DW (1998) Marine mammals of the world: systematics and distribution. The Society for Marine Mammalogy Spec Publ 4. Allen Press, Lawrence, KS

* Risch D, Gales NJ, Gedamke J, Kindermann L and others (2014) Mysterious bio-duck sound attributed to the Antarctic minke whale (Balaenoptera bonaerensis). Biol Lett 10:20140175

Rockwood RC, Calambokidis J, Jahncke J (2017) High mortality of blue, humpback and fin whales from modeling of vessel collisions on the US West Coast suggests population impacts and insufficient protection. PLOS ONE 12: e0183052

Rosel PE, Wilcox LA (2014) Genetic evidence reveals a unique lineage of Bryde's whales in the northern Gulf of Mexico. Endang Species Res 25:19-34

* Samaran F, Adam O, Guinet C (2010a) Discovery of a midlatitude sympatric area for two Southern Hemisphere blue whale subspecies. Endang Species Res 12:157-165

Samaran F, Adam O, Guinet C (2010b) Detection range modeling of blue whale calls in Southwestern Indian Ocean. Appl Acoust 71:1099-1106 
Samaran F, Stafford KM, Branch TA, Gedamke J, Royer JY, Dziak RP, Guinet C (2013) Seasonal and geographic variation of southern blue whale subspecies in the Indian Ocean. PLOS ONE 8:e71561

Šrović A, Branch T, Brownell Jr RL, Buchan S and others (2018) Blue whale song occurrence in the Southern Hemisphere. International Whaling Commission Scientific Committee Paper SC/67B/SH/11

Smith TD, Reeves RR, Josephson EA, Lund JN (2012) Spatial and seasonal distribution of American whaling and whales in the age of sail. PLOS ONE 7:e34905

Socheleau FX, Samaran F (2017) Detection of mysticete calls: a sparse representation-based approach. Collection des rapport de recherche d'IMT Atlantic. RR-201704-SC. https://hal.archives-ouvertes.fr/hal-01736178/ document

Socheleau FX, Leroy E, Pecci AC, Samaran F, Bonnel J, Royer JY (2015) Automated detection of Antarctic blue whale calls. J Acoust Soc Am 138:3105-3117

Stafford KM, Chapp E, Bohnenstiehl DR, Tolstoy M (2011) Seasonal detection of three types of 'pygmy' blue whale

Editorial responsibility: Mike Noad, Gatton, Queensland, Australia calls in the Indian Ocean. Mar Mamm Sci 27:828-840

Sutaria D, Sule M, Jog K, Bopardikar I, Panicker D, Jamalabad A (2016) Baleen whale records from the Arabian Sea, India from June, 2015-2016. International Whaling Commission Scientific Committee Paper SC/66B/SH/34

Sutaria D, Sule M, Jog K, Bopardikar I, Jamalabad A, Panicker D (2017) Baleen whale records from India. International Whaling Commission Scientific Committee Paper SC/67A/CMP/03

Watkins WA, Tyack PL, Moore KE, Bird JE (1987) The 20-Hz signals of finback whales (Balaenoptera physalus). J Acoust Soc Am 82:1901-1912

Watkins WA, Daher MA, Reppucci GM, George JE, Martin DL, DiMarzio NA, Gannon DP (2000) Seasonality and distribution of whale calls in the North Pacific. Oceanography 13:62-67

Willson A, Minton AG, Collins T, Al Harthi S and others (2019) Oman research update: documenting cetacean diversity and blue whale feeding habitat in Dhofar, southern Oman. International Whaling Commission Scientific Committee Paper SC/68A/CMP/08

Submitted: February 5, 2020; Accepted: November 13, 2020 Proofs received from author(s): December 11, 2020 